\title{
WestVirginiaUniversity
}

THE RESEARCH REPOSITORY @ WVU

Graduate Theses, Dissertations, and Problem Reports

2000

\section{Porosity distribution prediction using artificial neural networks}

\author{
Fahad Abdullah Al-Qahtani \\ West Virginia University
}

Follow this and additional works at: https://researchrepository.wvu.edu/etd

\section{Recommended Citation}

Al-Qahtani, Fahad Abdullah, "Porosity distribution prediction using artificial neural networks" (2000). Graduate Theses, Dissertations, and Problem Reports. 1010.

https://researchrepository.wvu.edu/etd/1010

This Thesis is protected by copyright and/or related rights. It has been brought to you by the The Research Repository @ WVU with permission from the rights-holder(s). You are free to use this Thesis in any way that is permitted by the copyright and related rights legislation that applies to your use. For other uses you must obtain permission from the rights-holder(s) directly, unless additional rights are indicated by a Creative Commons license in the record and/ or on the work itself. This Thesis has been accepted for inclusion in WVU Graduate Theses, Dissertations, and Problem Reports collection by an authorized administrator of The Research Repository @ WVU. For more information, please contact researchrepository@mail.wvu.edu. 


\title{
POROSITY DISTRIBUTION PREDICTION USING ARTIFICAL NEURAL NETWORKS
}

\author{
Fahad A. Al-Qahtani
}

\author{
Thesis Submitted to the \\ College of Engineering and Mineral Resources \\ at West Virginia University \\ In Partial Fulfillment of the Requirements \\ for the Degree of \\ Master of Science \\ In \\ Petroleum and Natural Gas Engineering
}

Khashayar Aminian, Ph.D., Chair

Daniel Della-Giustina, Ph.D.

Ilkin Bilgesu, Ph.D.

Samuel Ameri, M.S.

Department of Petroleum and Natural Gas Engineering

Morgantown, West Virginia

2000

Keywords: Logistic, Gaussian, Sigmoid, Vanilla, Iterative 


\title{
ABSTRACT
}

\section{POROSITY DISTRIBUTION PREDICTION USING ARTIFICAL NEURAL NETWORKS}

\author{
Fahad A. Al-Qahtani
}

Reservoir characterization plays a very important role in the petroleum industry, especially to the economic success of the reservoir development. Heterogeneity can complicate the evaluation of reservoir properties. Porosity is the primary key to a reliable reservoir model.

Several studies in the literature indicated that accurate evaluation of reservoir properties can be made by the analysis of electric logs. Stringtown oil field in Tyler and Wetzel counties in the northwestern part of West Virginia was selected to conduct this study.

Artificial Neural Networks (ANN) is one of the latest technologies available to the petroleum industry. The objective of this study was to predict reliable porosity values from geophysical log data. In this study, porosity predictions were compared against core measurements and were found to be reliable with $\mathrm{R}^{2}$ of 0.97 . The results confirmed the capability of using ANN. The results were utilized to map the Porosity distribution. 


\section{ACKNOWLEDGMENT}

The author wishes to express his sincere gratitude to the graduate thesis committee members:

Dr. Khashayar Amininan, advisor who directed the present investigation, for his help and support throughout the graduate program.

Grateful acknowledgment is also made to:

Professor Samuel Ameri, Dr. Ilkin Bilgesu, Dr. Daniel Della-Giustina for their useful advice, support and encouragement 


\section{TABLE OF CONTENTS}

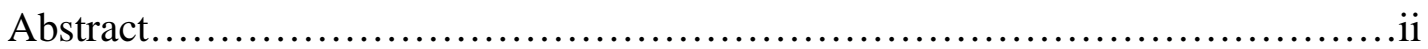

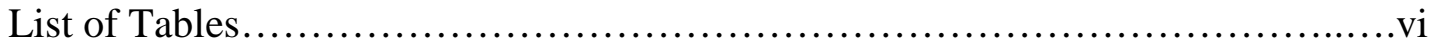

List of Figures...................................................... vi

Nomenclature..........................................................viii

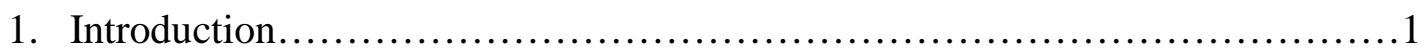

2. Literature Review................................................. 4

2.1 Study Area......................................................... 4

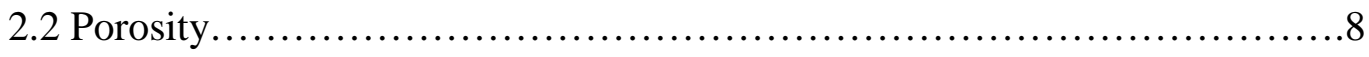

2.2.1 Definition......................................................

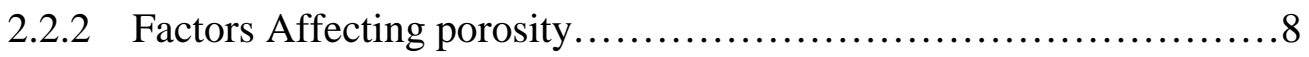

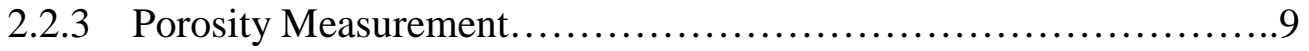

2.2.4 Porosity Evaluation from Well Logs.............................11

2.3 Artificial Neural Networks and its Applicability..........................11

2.3.1 Artificial Neural Network's Components...........................13

2.3.2 Architectures.............................................15

2.3.3 Algorithms..................................................

2.3.4 Activation Functions........................................ 18

2.3.5 Development............................................20

2.3.6 Training..................................................... 23

2.3.7 Verification.............................................28

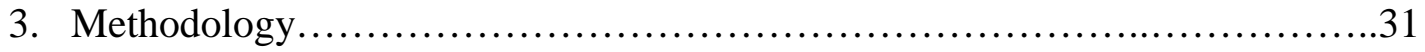

3.1 Objectives.................................................... 31 
3.2 Data Collection................................................... 32

3.3 Data Analysis.......................................................

3.4 Input Selection................................................ 37

3.5 Artificial Neural Network Training....................................39

3.6 Artificial Neural Network Verification...............................43

3.7 Artificial Neural network prediction...............................45

4. Results and Discussion................................................ 48

5. Conclusions and Recommendations..................................52

References............................................................ 54

Appendix I..........................................................56

Appendix II..............................................................60 


\section{LIST OF TABLES}

Table 1: Methods of Porosity Determination

Table 2: Cored Wells Information

Table 3: Average Core Depth Shifting

Table 4: Input Strength for Back-propagation Network

Table 5: General regression Neural Network Production Set Results

Table 6: Comparison of Porosity Predictions Results

Table 7: Back-Propagation Network Statistical Results

Table 8: GRNN Statistical Results

\section{LIST OF FIGURES}

Figure 1: Stringtown Field Location in West Virginia

Figure 2: Stringtown Oil Field Map

Figure 3: Stringtown Field Well Location

Figure 4: A Simple Artificial Neural Network

Figure 5: Training of an ANN by Back-Propagation

Figure 6: Assuring good Generalization of ANN

Figure 7: Core Porosity vs. Log Porosity for Well 095-1125

Figure 8: Porosity and Log Responses vs. Depth for Well 095-1124

Figure 9: Derivative Calculation Using the Three Point Method

Figure 10: Porosity Prediction by Back-Propagation vs. Actual Core Porosity

Figure 11: Porosity Prediction by GRNN vs. Actual Core Porosity 
Figure 12: Correlation of Actual Core Porosity and GRNN Predictions in the Test Set

Figure 13: Porosity Profile based on forecast for Cored Well 095-1126

Figure 14: Correlation between GRNN Porosity Predictions vs. Log Porosity

Figure 15: Porosity Correlation for All Wells

Figure 16: Correlation of Actual Core Porosity and Back-Propagation Predictions

Figure 17: Porosity Distribution Map for the Stringtown Field

Figure I - 1: Core Porosity vs. Log Porosity for Well 095-0741

Figure I - 2: Core Porosity vs. Log Porosity for Well 095-0859

Figure I - 3: Core Porosity vs. Log Porosity for Well 095-1124

Figure I - 4: Core Porosity vs. Log Porosity for Well 095-1126

Figure I - 5: Core Porosity vs. Log Porosity for Well 103-1315

Figure I - 6: Core Porosity vs. Log Porosity for Well 103-1547

Figure II - 1: Core Porosity and Log Responses vs. Depth for Well 095-0741

Figure II - 2: Core Porosity and Log Responses vs. Depth for Well 095-0859

Figure II - 3: Core Porosity and Log Responses vs. Depth for Well 095-1125

Figure II - 4: Core Porosity and Log Responses vs. Depth for Well 095-1126

Figure II - 5: Core Porosity and Log Responses vs. Depth for Well 103-1315

Figure II - 6: Core Porosity and Log Responses vs. Depth for Well 103-1547 


\section{NOMENCLATURE}

$\phi=$ Porosity $[\%]$

$\mathrm{V}_{b}=$ bulk volume of the rock $\left[\mathrm{ft}^{3}\right]$

$\mathrm{V} g=$ grain volume $\left[\mathrm{ft}^{3}\right]$

$\rho_{m}=$ matrix density $[\mathrm{gr} / \mathrm{cc}]$

$\rho b=$ bulk density $[\mathrm{gr} / \mathrm{cc}]$

$\rho f=$ fluid density [gr/cc]

r squared $=$ the square of the correlation coefficient 


\section{CHAPTER 1 \\ INTRODUCTION}

The study presented here is a summary of a theoretical and test activities developed as a part of an elaborate work model which aims at characterizing the Stringtown field in Tyler and Wetzel counties in the northwestern part of West Virginia.

Initially, electric logs were used mostly for the determination of formation tops and bottoms, and also for determining the oil-water contact. Later, electric logs were used to evaluate most of the reservoir properties such as porosity, permeability, fluid saturation, temperature, reservoir pressures, type of formation and mineral identification. Several studies imply that accurate evaluation of reservoir properties can be made by analysis of electric logs [1], [2], [3]. However, the interpretation of electric logs is not free of error, and care must be exercised when evaluating a reservoir by electric logs.

Characterizing a reservoir is a very complex task, due to its inherent heterogeneity. Heterogeneous reservoirs are known for the variation in their properties within a small area. Distinct geological ages, nature of rock, depositional environments are some of the reasons behind the heterogeneity of a formation. Reservoir characterization plays a very important role in the petroleum industry, especially to the economic success of a reservoir development. 
Porosity is one of the fundamental properties of reservoir rocks and it is a measure of the void space in a rock. Porosity normally obtained either with wireline logs or by direct measurements on core samples. Coring is one of the oldest and still practiced technique. However, coring every well in a large field is a time consuming practice and can be very expensive.

Geophysical logs are available for most of the wells, while cores and well tests are available from few wells in the reservoir. Therefore, the evaluation of porosity from well $\log$ data is an important step to minimize cost. Better estimation of porosity can be obtained when the latest technology available is applied.

Artificial Neural Networks is one of the latest technologies available to the petroleum industry. Neural Networks can predict reliable porosity values from geophysical log data regardless of the limited number of cored well in the field. Beside the fact that a good prediction of porosity can be achieved, also porosity distribution can be mapped using Neural Network.

The goal of this research is to predict a reliable porosity and map the porosity distribution in the Stringtown field using Gamma Ray (GR) and Bulk Density (RHOB) logs, which are available from most of the wells in the field. The geophysical logs for over 120 wells were used to map porosity throughout the entire reservoir. 
A primary key to a reliable reservoir model is porosity distribution. In this case, porosity distribution can improve the accuracy of reservoir model prediction. The accurate knowledge of porosity distribution can enhance waterflood operation prediction of the waterflood performance. 


\section{CHAPTER 2}

\section{LITERATURE REVIEW}

\subsection{Study Area}

The Stringtown Oil Field is located on the borderline between Tyler and Wetzel Counties in the northwestern part of West Virginia. The field is about 5 miles long (north-south trend) and 2.5 miles wide. The total productive area is approximately 5200 acres. The primary pay zone in the field is the upper Devonian Gordon Sandstone. The average depth of the pay zone is 2955 feet. The pay zone is generally 10 to 12 feet thick. The wells are generally completed as open hole. The oil in the Stringtown Field has a gravity of $44^{\circ} \mathrm{API}$ at $60^{\circ} \mathrm{F}$, viscosity of $3.5 \mathrm{cp}$. at atmospheric pressure and $75^{\circ} \mathrm{F}$.

Figure 1. Location of the Stringtown Oil Field in West Virginia

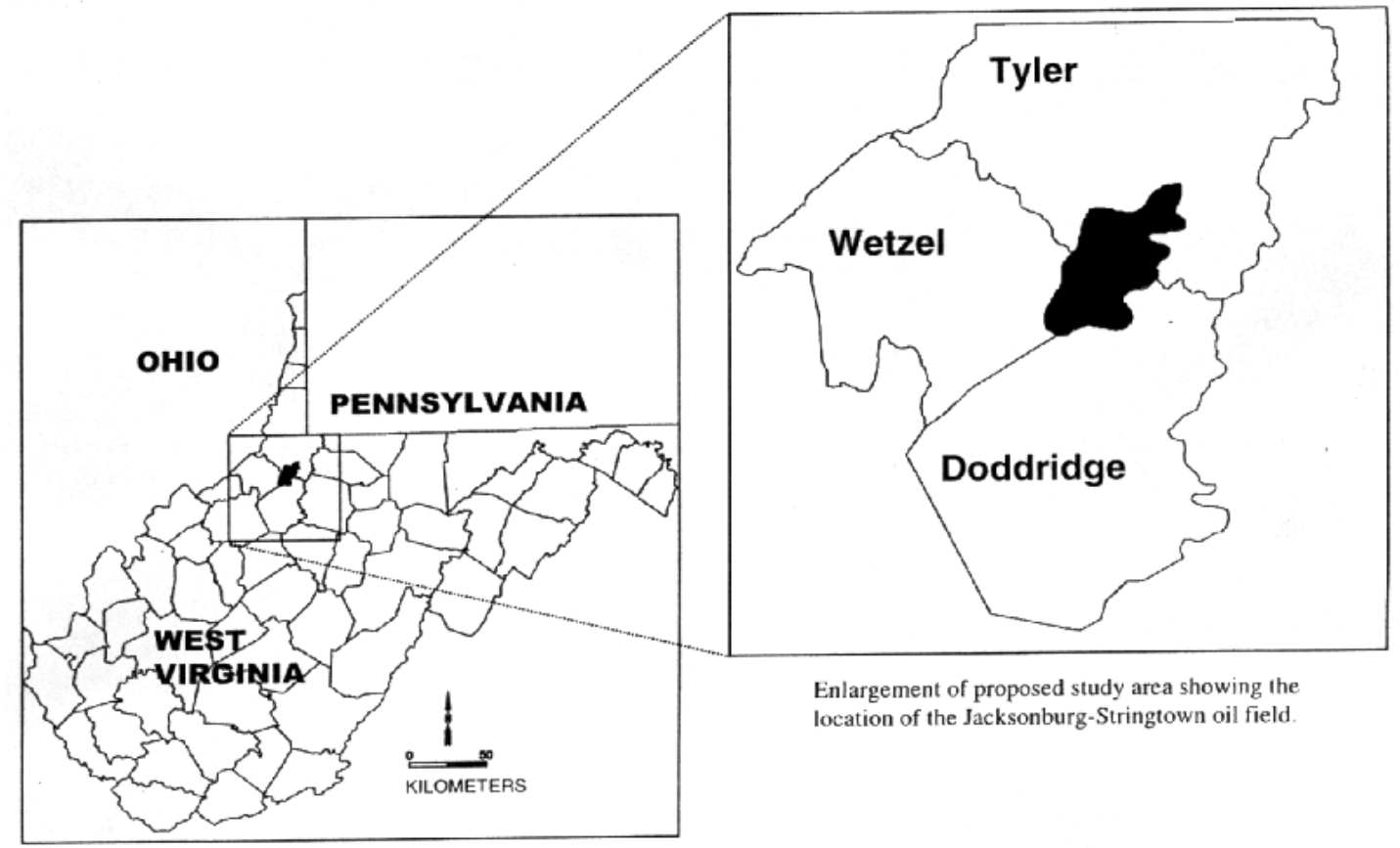


The primary production was the result of the solution gas drive and gravity drainage, which started in the early 1890s and lasted until mid 1920. A gas recycle project was initiated in mid 1940's, with poor results accounted for about $10 \%$ of total production. Total oil production, including primary and secondary recovery is estimated to be 7,500,000 barrels.

Dual-five-spot waterflood pilot operation began in 1980 and lasted until 1985. Since then, waterflood developments are carried throughout the field in similar patterns. Figure 2 shows a map of the Stringtown Oil Field. A map with the location of cored, pilot waterflood and digitized wells is shown in Figure 3. 
Figure 2 Stringtown Oil Field Map

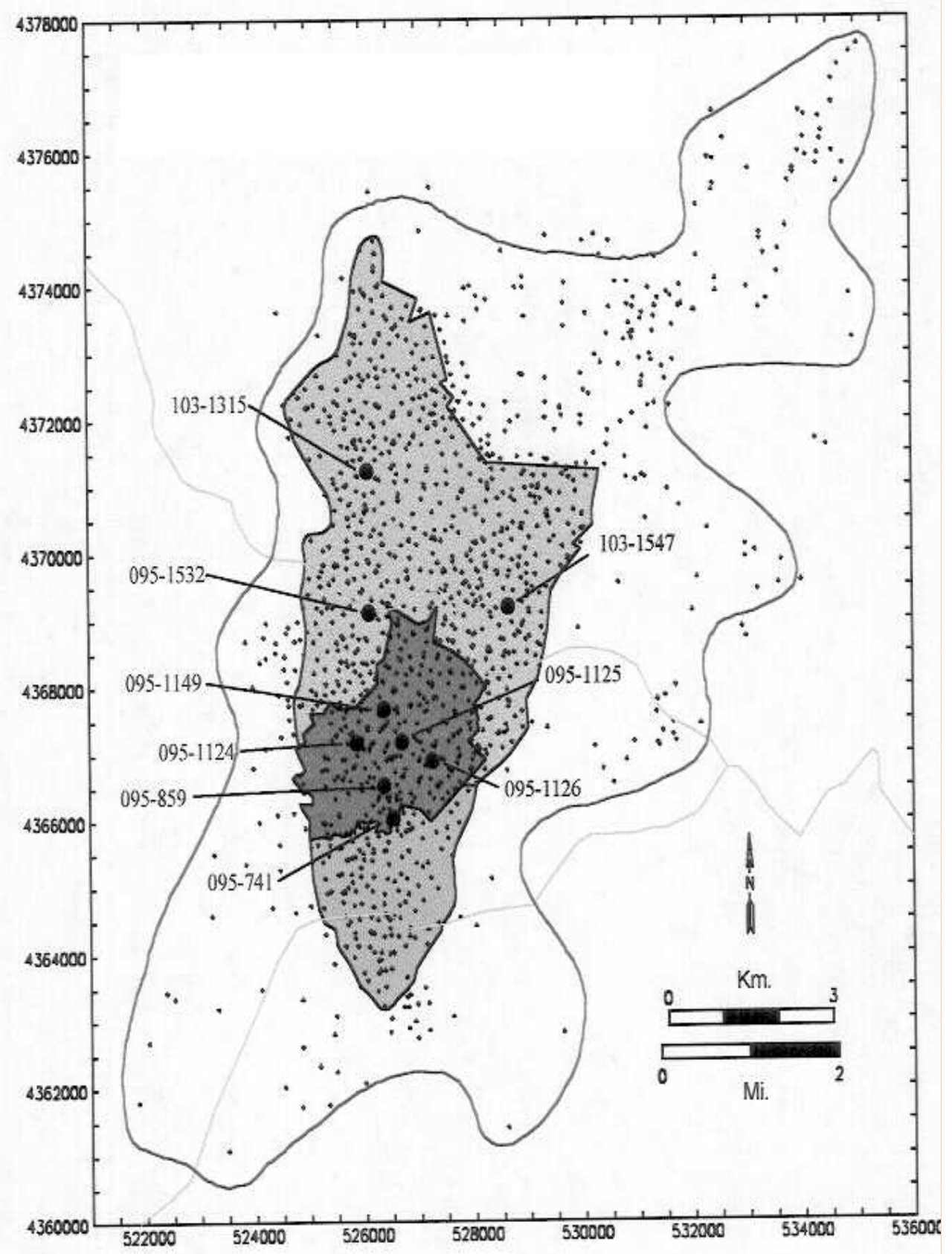


Figure 3 Stringtown Field Well Location

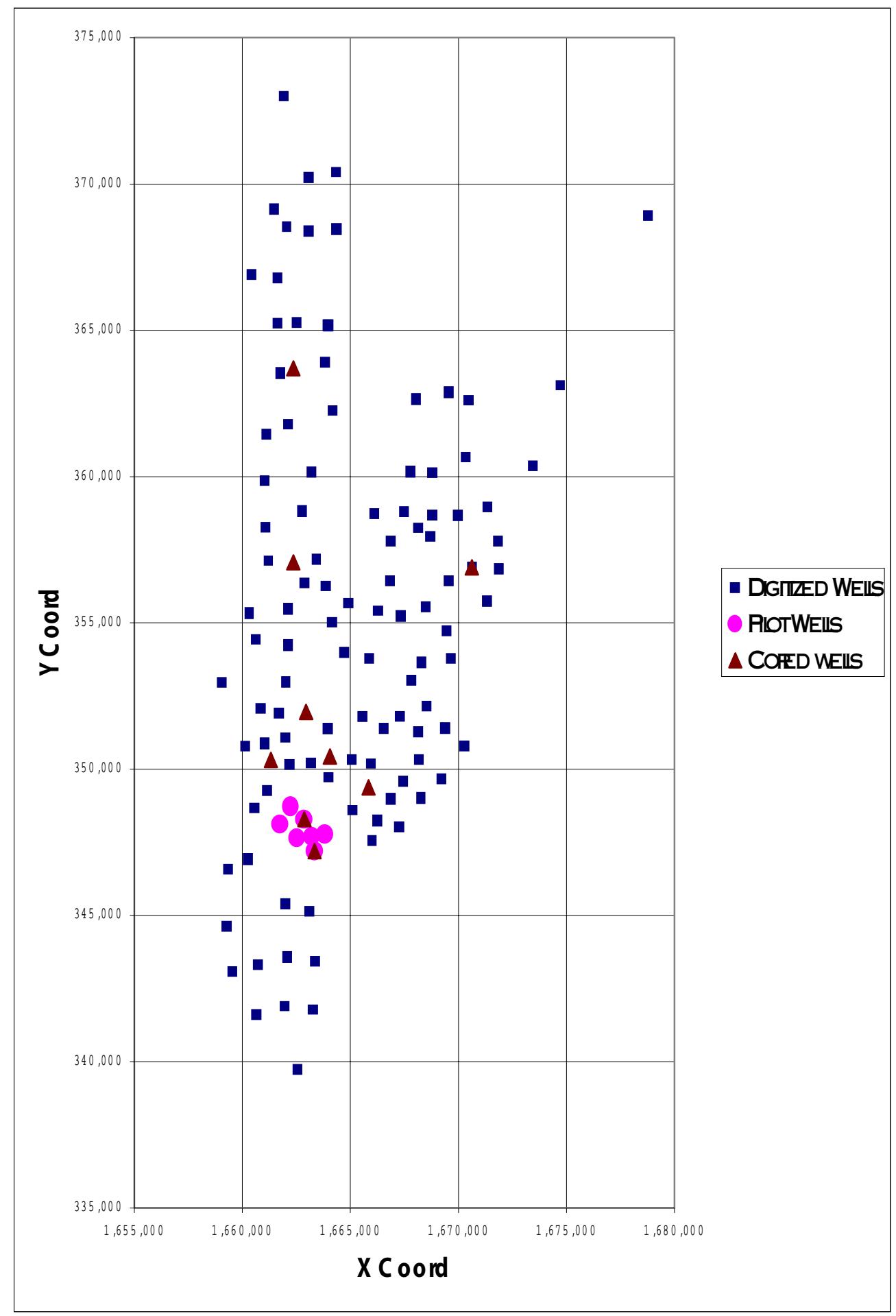




\subsection{Porosity}

\subsubsection{Definition}

Porosity is one of the fundamental elements in petroleum engineering. Porosity is a measure of a void space within a rock, expressed as a percentage of the bulk volume of the rock. This can be written as:

$$
\phi=\frac{\mathrm{V} b-\mathrm{V} g}{\mathrm{~V} b}
$$

$$
\begin{aligned}
& \text { Where: } \begin{aligned}
\phi & =\text { porosity }[\%] \\
\mathrm{V} b & =\text { bulk volume of the rock }\left[\mathrm{ft}^{3}\right] \\
\mathrm{V} g & =\text { grain volume }\left[\mathrm{ft}^{3}\right]
\end{aligned}
\end{aligned}
$$

Porosity can be classified into two categories: absolute and effective porosity. Absolute porosity is the total porosity of the rock regardless of connections among the voids. Effective porosity is the voids that are interconnected.

\subsubsection{Factors Affecting Porosity}

The porosity of petroleum reservoirs range from $5 \%$ to $40 \%$ but most frequently are between $10 \%$ to $20 \%$. The factors affecting the magnitude of porosity are:

1. Sorting or grain size distribution

2. Degree of cementation or consolidation 
3. Packing

4. Chemical reaction

5. Shape

6. Fracturing

7. Deformation by the stresses

\subsubsection{Porosity Measurement}

Several methods have been developed for the determination of porosity of consolidated rocks having intergranular porosity. However, formation porosity is commonly measured in the laboratories using core sample. Diamond coring equipment was used to obtain core samples with a diameter of 3.5 inches. There are three basic parameters required to determine porosity:

\section{Bulk Volume}

2. Pore Volume

\section{Grain Volume}

In the laboratory measurement of porosity, it is necessary to determine only two of the three basic parameters. In general, all methods of bulk volume determination are applicable to determining both total and effective porosity. Determination of bulk volume volumetrically uses a variety of specially constructed pycnometers or volumeters. The various methods of porosity determination are illustrated in Table 1. 
Table 1 Methods of Porosity Determination, after [4]

\begin{tabular}{|c|c|c|c|c|c|c|c|c|}
\hline $\begin{array}{l}\text { What is } \\
\text { Obtained }\end{array}$ & $\begin{array}{c}\text { Effective } \\
\text { porosity }\end{array}$ & $\begin{array}{c}\text { Effective } \\
\text { porosity }\end{array}$ & $\begin{array}{c}\text { Effective } \\
\text { porosity }\end{array}$ & $\begin{array}{c}\text { Effective } \\
\text { porosity }\end{array}$ & $\begin{array}{c}\text { Effective } \\
\text { porosity }\end{array}$ & $\begin{array}{c}\text { Effective } \\
\text { porosity }\end{array}$ & $\begin{array}{c}\text { Effective } \\
\text { porosity }\end{array}$ & $\begin{array}{c}\text { Total } \\
\text { porosity }\end{array}$ \\
\hline Method & $\begin{array}{l}\text { Washburn- } \\
\text { Bunting }\end{array}$ & Stevens & Kobe & Boyle & Saturation & $\begin{array}{c}\text { Core lab wet } \\
\text { samples }\end{array}$ & $\begin{array}{c}\text { Core lab dry } \\
\text { samples }\end{array}$ & $\begin{array}{c}\text { Sand } \\
\text { Density }\end{array}$ \\
\hline $\begin{array}{c}\text { Type of } \\
\text { sampling }\end{array}$ & $\begin{array}{c}\text { One to } \\
\text { several } \\
\text { pieces per } \\
\text { increment }\end{array}$ & $\begin{array}{c}\text { One to } \\
\text { several } \\
\text { pieces per } \\
\text { increment }\end{array}$ & $\begin{array}{c}\text { One to } \\
\text { several } \\
\text { pieces per } \\
\text { increment }\end{array}$ & $\begin{array}{c}\text { One to } \\
\text { several } \\
\text { pieces per } \\
\text { increment }\end{array}$ & $\begin{array}{c}\text { One to } \\
\text { several } \\
\text { pieces per } \\
\text { increment }\end{array}$ & $\begin{array}{l}\text { Several } \\
\text { pieces for } \\
\text { retort one for } \\
\text { mercury } \\
\text { pump }\end{array}$ & $\begin{array}{c}\text { One to } \\
\text { several } \\
\text { pieces per } \\
\text { increment }\end{array}$ & $\begin{array}{c}\text { Several } \\
\text { pieces per } \\
\text { increment }\end{array}$ \\
\hline Preparation & $\begin{array}{c}\text { Solvent } \\
\text { extraction } \\
\text { and oven } \\
\text { drying. } \\
\text { Occasionall } \\
\text { y use retort } \\
\text { samples }\end{array}$ & $\begin{array}{c}\text { Solvent } \\
\text { extraction } \\
\text { and oven } \\
\text { drying. } \\
\text { Occasionally } \\
\text { use retort } \\
\text { samples }\end{array}$ & $\begin{array}{c}\text { Solvent } \\
\text { extraction } \\
\text { and oven } \\
\text { drying. } \\
\text { Occasionally } \\
\text { use retort } \\
\text { samples }\end{array}$ & $\begin{array}{c}\text { Solvent } \\
\text { extraction } \\
\text { and oven } \\
\text { drying. } \\
\text { Occasionally } \\
\text { use retort } \\
\text { samples }\end{array}$ & $\begin{array}{c}\text { Solvent } \\
\text { extraction } \\
\text { and oven } \\
\text { drying. } \\
\text { Occasionally } \\
\text { use retort } \\
\text { samples }\end{array}$ & None & $\begin{array}{c}\text { Solvent } \\
\text { extraction } \\
\text { and oven } \\
\text { drying. } \\
\text { Occasionally } \\
\text { use retort } \\
\text { samples }\end{array}$ & $\begin{array}{l}\text { Extraction } \\
\text { and } \\
\text { crushing } \\
\text { the } \\
\text { sample to } \\
\text { grain size }\end{array}$ \\
\hline $\begin{array}{l}\text { Function } \\
\text { measured }\end{array}$ & $\begin{array}{c}\text { Pore } \\
\text { volume and } \\
\text { bulk } \\
\text { volume }\end{array}$ & $\begin{array}{l}\text { Sand grain } \\
\text { volume } \\
\text { unconnected } \\
\text { pore volume } \\
\text { and bulk } \\
\text { volume }\end{array}$ & $\begin{array}{l}\text { Sand grain } \\
\text { volume } \\
\text { unconnected } \\
\text { pore volume } \\
\text { and bulk } \\
\text { volume }\end{array}$ & $\begin{array}{l}\text { Sand grain } \\
\text { volume } \\
\text { unconnected } \\
\text { pore volume } \\
\text { and bulk } \\
\text { volume }\end{array}$ & $\begin{array}{l}\text { Pore volume } \\
\text { and bulk } \\
\text { volume }\end{array}$ & $\begin{array}{l}\text { Volumes of } \\
\text { gas space, oil } \\
\text { and water } \\
\text { and bulk } \\
\text { volume }\end{array}$ & $\begin{array}{l}\text { Sand grain } \\
\text { volume } \\
\text { unconnected } \\
\text { pore volume } \\
\text { and bulk } \\
\text { volume }\end{array}$ & $\begin{array}{c}\text { Bulk } \\
\text { volume } \\
\text { and solid } \\
\text { volume }\end{array}$ \\
\hline $\begin{array}{c}\text { Manner of } \\
\text { measurement }\end{array}$ & $\begin{array}{c}\text { Reduction } \\
\text { of pressure } \\
\text { on a } \\
\text { confined } \\
\text { sample and } \\
\text { measureme } \\
\text { nt of air } \\
\text { involved }\end{array}$ & $\begin{array}{c}\text { Difference in } \\
\text { volume of air } \\
\text { evolved from } \\
\text { a constant } \\
\text { volume } \\
\text { chamber } \\
\text { when empty } \\
\text { and when } \\
\text { occupied by } \\
\text { sample. Bulk } \\
\text { volume by } \\
\text { Russel tube }\end{array}$ & $\begin{array}{c}\text { Difference in } \\
\text { volume of air } \\
\text { evolved from } \\
\text { a constant } \\
\text { volume } \\
\text { chamber } \\
\text { when empty } \\
\text { and when } \\
\text { occupied by } \\
\text { sample. Bulk } \\
\text { volume by } \\
\text { Russel tube }\end{array}$ & $\begin{array}{c}\text { Difference in } \\
\text { volume of air } \\
\text { evolved from } \\
\text { a constant } \\
\text { volume } \\
\text { chamber } \\
\text { when empty } \\
\text { and when } \\
\text { occupied by } \\
\text { sample. Bulk } \\
\text { volume by } \\
\text { Russel tube }\end{array}$ & $\begin{array}{l}\text { Weight of } \\
\text { dry sample } \\
\text { weight of } \\
\text { saturated } \\
\text { sample in } \\
\text { air, weight of } \\
\text { saturated } \\
\text { sample } \\
\text { immersed in } \\
\text { saturated } \\
\text { fluid }\end{array}$ & $\begin{array}{c}\text { Weight of } \\
\text { retort } \\
\text { sample, } \\
\text { volume of oil } \\
\text { and water } \\
\text { from retort } \\
\text { sample, gas } \\
\text { volume and } \\
\text { bulk volume } \\
\text { of sample }\end{array}$ & $\begin{array}{l}\text { Difference in } \\
\text { volume of air } \\
\text { evolved from } \\
\text { a constant } \\
\text { volume } \\
\text { chamber } \\
\text { when empty } \\
\text { and when } \\
\text { occupied by } \\
\text { sample. }\end{array}$ & $\begin{array}{l}\text { Weight of } \\
\text { dry } \\
\text { sample, } \\
\text { weight of } \\
\text { saturated } \\
\text { sample } \\
\text { immersed } \\
\text { weight } \\
\text { and } \\
\text { volume of } \\
\text { sand } \\
\text { grains }\end{array}$ \\
\hline Error & $\begin{array}{c}\text { Air from } \\
\text { dirty } \\
\text { mercury, } \\
\text { possible } \\
\text { leaks in } \\
\text { system, } \\
\text { incomplete } \\
\text { evacuation } \\
\text { due to rapid } \\
\text { operation }\end{array}$ & $\begin{array}{c}\text { Possible } \\
\text { leaks in the } \\
\text { system, } \\
\text { incomplete } \\
\text { evacuation } \\
\text { due to rapid } \\
\text { operation }\end{array}$ & $\begin{array}{l}\text { Possible } \\
\text { leaks in the } \\
\text { system, } \\
\text { incomplete } \\
\text { evacuation } \\
\text { due to rapid } \\
\text { operation }\end{array}$ & $\begin{array}{l}\text { Possible } \\
\text { leaks in the } \\
\text { system, } \\
\text { incomplete } \\
\text { evacuation } \\
\text { due to rapid } \\
\text { operation }\end{array}$ & $\begin{array}{c}\text { Possible } \\
\text { incomplete } \\
\text { saturation }\end{array}$ & $\begin{array}{c}\text { Obtain } \\
\text { excess water } \\
\text { from shales. } \\
\text { Loss of } \\
\text { vapors } \\
\text { through } \\
\text { condensers }\end{array}$ & $\begin{array}{c}\text { Possible } \\
\text { leaks in the } \\
\text { system, } \\
\text { incomplete } \\
\text { evacuation } \\
\text { due to rapid } \\
\text { operation }\end{array}$ & $\begin{array}{l}\text { Possible } \\
\text { loss of } \\
\text { sand } \\
\text { grains in } \\
\text { crushing }\end{array}$ \\
\hline
\end{tabular}




\subsubsection{Porosity Evaluation from Well Logs}

The porosity can be determined from a measurement of its bulk density. The fundamental equation that relates the bulk density, $\rho b$, to the solid matrix, which has a density $\rho m$, and the porosity $\phi$, which contains a fluid of density $\rho f$, is

$$
\rho b=\phi \rho f+(1-\phi) \rho m
$$

From this relationship, the porosity, $\phi$, can be determined from the measurement of bulk density, assuming that the matrix density and fluid density are known. These will be known with any precision only if the fluid type and properties and lithology are known. In practical terms, the density ranges of fluid is between 0.8 and $1.2 \mathrm{gr} / \mathrm{cc}$, and most matrix densities are between 2.60 and $2.96 \mathrm{gr} / \mathrm{cc}$ [4].

\subsection{Artificial Neural Networks and its Applicability}

The first conceptual elements of Neural Networks were introduced in the mid1940, and the concept developed gradually until the 1970's. Artificial Neural Networks (ANN) are used in different areas: from finances to engineering, from medicine to administration, from social studies to management.

The most significant steps in developing the robust theoretical aspects of this new method were made during the explosion in computer technology and use of artificial intelligence. Properties that make Neural Networks suitable for intelligent control applications include the following [5]: 
- Learning by experience (human -like learning behavior).

- Ability to generalize (map similar input to similar outputs).

- Parallel distributed processing.

- Robust in the presence of noise.

- Multivariable capabilities.

There are many examples of neural network applications in the petroleum industry, from exploration, reservoir and production engineering, drilling operations [2].

An artificial neural network is a system of several simple processing units known as nodes, neurons, or processing elements. These processing elements are associated with one another through simple connections known as synaptic connections. The strength of the synaptic connections changes with attaching a weight to them. Neurons in a network are organized in layers, each layer is responsible for a particular task [1].

Typically, there are three kinds of layers in an artificial neural network. Input layer is responsible for presenting the network with the necessary information from the outside world in a normalized manner. Hidden layers (there may be more than one hidden layer in a network, a problem-dependent factor) contain neurons that are responsible for the main part of the input to the output mapping. Output layer contains output neurons that communicate the outcome of the neural network computation with the user [1]. 


\subsubsection{Artificial Neural Network's Components}

In order to understand how an Artificial Neural Networks work, one must become familiar with its components.

- Neurons: is the very essential element of (ANN). Neurons are elemental processors that execute simple tasks. Neurons apply a mathematical activation function to process the information that is received as an input and produce an output as a result. As the biological nervous system, neurons are connected through links, which transmit the signals among them. Each connection link has an associated weight that, in turns, modify the signal transmitted.

- Slabs: Often, Neurons are grouped in so-called Slabs. Similarly, Slabs are grouped in Layers. 
- Layers: a typical artificial neural network consists of three layers: Input, Middle and Output Layer. The Input Layer receives information (set of features representing the pattern) from the environment or surroundings and transmits it to the Middle Layer. Every Neuron located in the Input Layer is interconnected with all of the Neurons in the Middle Layer, such that the information processing task is carried out parallel and simultaneously. In the same way, the Middle layer is interconnected to the Output Layer. The Middle Layer is the one that actually analyzes the information supplied from the environment to the ANN. The Output Layer receives this analysis and converts it into a meaningful interpretation to communicate it back to the environment. A simplistic schematic of an ANN is shown in Figure 4.

Figure 4 A simple Artificial Neural Network

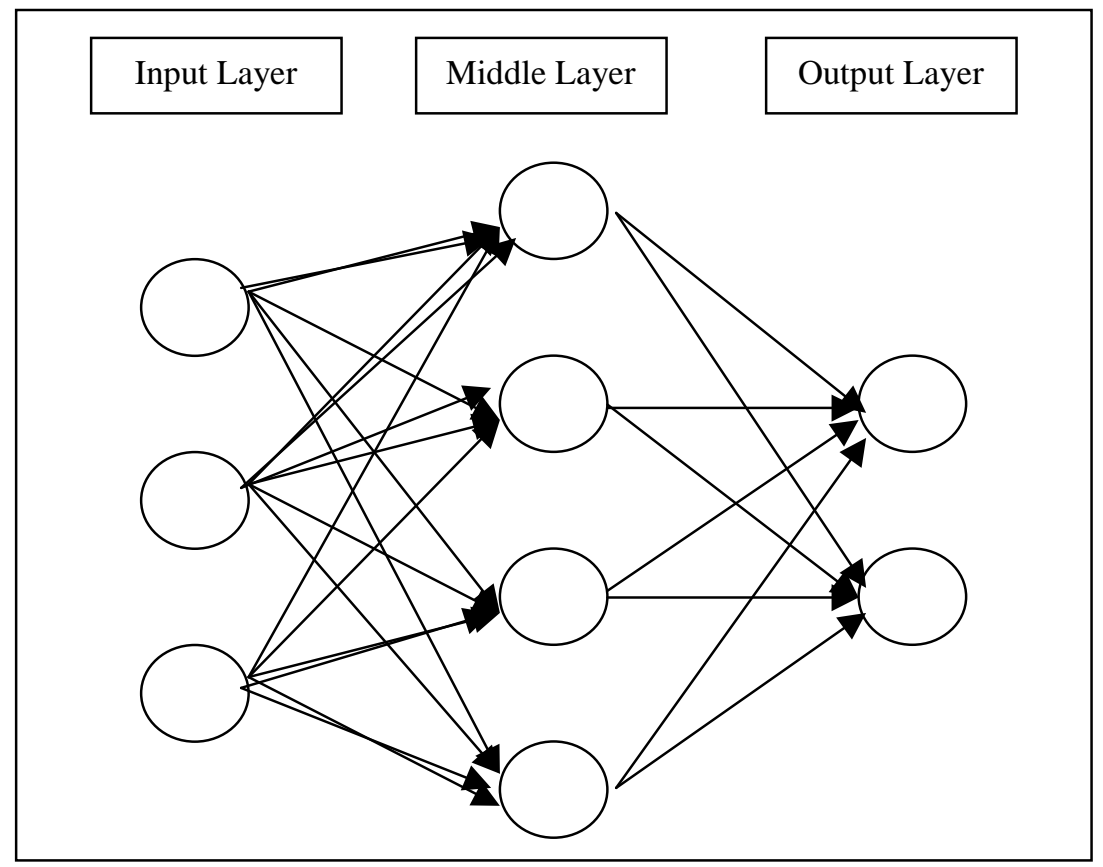




\subsubsection{Architecture}

The Neural Network's Architecture or its pattern of connectivity defines how much knowledge is stored in it. It also determines the algorithm to be used in updating the weights of each connection. There are several architectures and learning paradigms have been developed over past years [6]. The following sections discuss some of the main architectures:

\section{Backpropagation Models}

Backpropagation networks are known for their prediction capabilities and ability to generalize well on a wide variety of problems. These models are a supervised type of networks, in other words, trained with both inputs and target outputs. Some of the major nets are listed below:

- Standard Nets: each layer connected to the immediately previous layer.

- Jump Connection Nets: each layer connected to every previous layer

- Recurrent networks with dampened feedback from either the input, hidden, or output layer.

- Ward networks with multiple slabs in the middle layer: these networks are very powerful when each hidden slab is given a different activation function from the other slabs because they detect different features of the input vectors. This gives the output layer different viewpoints of the data. 


\section{General Regression Neural Network (GRNN)}

General Regression Neural Network is a type of supervised network and also trains quickly on sparse data sets but, rather than categorizing it, GRNN applications are able to produce continuous valued outputs. GRNN is a three-layer network where there must be one hidden neuron for each training pattern. There are no training parameters such as the learning rate and momentum as in Backpropagation, but there is a smoothing factor, that is applied after the network is trained. The smoothing factor must be greater than 0 and can usually range from 0.1 to 1 with good results. GRNN can have multidimensional input, and it will fit multidimensional surfaces through data. The number of neurons in the input layer is the number of inputs in your problem, and the number of neurons in the output layer corresponds to the number of outputs. Because GRNN networks evaluate each output independently of the other outputs, GRNN networks may be more accurate than Backpropagation networks when there are multiple outputs.

\section{Unsupervised (Kohonen)}

The Kohonen Self Organizing Map network is a type of unsupervised network, and its architecture is the simplest of all with only two layers: input and output. The Kohonen network has the ability to learn without being shown correct outputs in sample patterns. These networks are able to separate data patterns into a specified number of classes. 


\section{Probabilistic Neural Network (PNN)}

This network is a type of supervised network known for their ability to train quickly on sparse data sets. PNN also separates data into a specified number of output categories.

\section{GMDH Network (Group Method of Data Handling or Polynomial Nets)}

GMDH works by building successive layers with links that are simple polynomial terms, which are created by using linear and non-linear regression. GMDH can build very complex models while avoiding overfitting problems.

\subsubsection{Algorithms}

The algorithm defines how the weights on the connections are updated. This requires a specification of the network's architecture. In some models new values of weights associated to links are determined at a regular time and applied to all units simultaneously, while in other models the rule is applied to a certain number of connection links at a time.

Since in ANN's, a specific mapping is implemented through the learning process by adjusting the weights, the algorithm and the network's response to a training signal become of paramount importance. There are two basic classes of learning in paralleldistributed processing models: associative learning and regularity detectors. In the associative learning, the goal is to learn the association between patterns such that if the network is exposed to noisy or a good pattern, it will respond with the appropriate output. 
This association is either hetero-association or auto-association. In hetero-associative learning two distinctive patterns are shown to the network, the input pattern and the required output. Whereas for auto-associative systems, the same pattern is used for both input and output.

No output is provided for regularity detectors, the unit will learn to respond to certain features depending on an internal teaching function and the nature of the input patterns. In this case, it is said that system undertakes an unsupervised learning.

\subsubsection{Activation Functions}

The basic operation of an artificial neuron involves summing its weighted input signal and applying an activation function to it, which as a result produces an output signal to be transmitted to the next layer. Activation functions may be divided into four categories: linear, binary, sigmoid and probabilistic. The most common functions are listed below:

1. Linear Functions:

- Identity: $f(x)=x$

- Linear Scaled: $f(x)=m x+b$

These functions are used primarily in the input layer so that the input pattern data set is passed just as is to the middle layer. 


\section{Binary Functions:}

- Step: $f(x)=1$ if $\mathrm{x} \geq \mathrm{b}$ or $f(x)=0$ if $\mathrm{x}<\mathrm{b}$

This function is utilized to convert continuo data into a binary unit. This feature is very helpful when building net to establish classes or categories

\section{Sigmoid Functions:}

- Logistic: $f(x)=\frac{1}{\left(1+e^{-\sigma x}\right)}$

- Hyperbolic Tangent: $f(x)=\tanh (x)$

- Hyperbolic Tangent 1.5: $f(x)=\tanh (1.5 x)$

- Symmetric Logistic: $f(x)=\frac{2}{\left(1+e^{-\sigma x}\right)}-1$

Sigmoid functions (S-shaped curves) are useful activation functions. They are especially advantageous for use in neural nets trained by the back-propagation paradigm, because the simple relationship between the value of the function at a point and the value of the derivative at that point reduces the computational overburden during training.

\section{Probabilistic Functions:}

- Gaussian: $f(x)=e^{-x^{2}}$

- Gaussian Complement: $f(x)=1-e^{-x^{2}}$

The probabilistic functions are unique in ANN's applications, because unlike the others, they are not increasing functions. The Gaussian function is the classic bell shaped 
curve, which maps high values into low ones, and maps mid-range values into high ones. It brings out meaningful characteristics not found at the extreme ends of the sum of weighted values. On the other hand, the Gaussian Complement function tends to bring out meaningful characteristics in the extremes of the data. Both functions are very useful in Ward networks.

\subsubsection{Development}

Several studies have imply that evaluating reservoir properties such as porosity and permeability from geophysical logs is possible through Artificial Neural Networks $(\mathrm{ANN})$ with a great deal of accuracy [1], [2], [3], [10], [12], [13]. In order to obtain reliable results of the porosity predictions, two artificial neural network architectures, Back-propagation and general regression networks were used, for the comparison purposes.

The following segments discuss the development of each network.

1. The Three-Layer Back-Propagation Network:

The three layer Back-propagation network with three slabs in the middle layer, each slab having a different activation function is one of the most appropriate architecture to make forecasts, because of its prediction capabilities and ability to generalize well on a wide variety of problems.

This type of network is very powerful when each middle slab is given a different activation function from the other slabs because they detect different features of the input 
vectors. This gives the output layer three different viewpoints of the data simultaneously. The activation functions used for the middle slabs in this model were a sigmoid function (hyperbolic tangent) and two probabilistic functions (Gaussian and Gaussian complement).

Sigmoid functions are very useful since they stresses the range of the input data so if it is not above a certain value a weak output is transmitted, in other words, it detects the amount of its preferred feature present. On the other hand, probabilistic functions are unique in ANN's applications, because unlike other sigmoid activation functions, they are not increasing functions. The Gaussian function maps high values into low ones, and maps mid-range values into high ones.

The number of neurons in the input layer is naturally the same as number of relevant variables describing the features of the object in this case of study, seven relevant variables are defined in the input layer. Since there is only one output variable to predict that is core porosity, a neuron is used in the output layer. The net sets the number of neurons in the middle layer.

\section{The Three-layers General Regression Neural Network:}

General Regression Neural Networks are known for the ability to train quickly on sparse data sets. GRNN work by measuring how far given samples pattern is from patterns in the training set. The output that is predicted by the network is a proportional 
amount of all the output in the training set. The proportion is based upon how far the new pattern is from the given patterns in the training set.

GRNN networks work by comparing patterns based upon their distance from each other. There are two methods to compute this distance, however Vanilla or Euclidean distance metric was recommended by the net because it works the best. We used Calibration to decide which smoothing factor is best for the problem. The success of GRNN network is dependent upon the smoothing factor. We used Genetic adaptive, which uses a genetic algorithm to find appropriate individual smoothing factors for each input as well as an overall smoothing factor. The input smoothing factor is an adjustment used to modify the overall smoothing factor to provide a new value for each input. However, training takes longer than the iterative option.

At the end of training, the individual smoothing factors may be used as a sensitivity analysis tool: the larger the factor for a given input, the more important that input to the model at least as far as the test set is concerned. You may want to use the genetic adaptive option when the input variables are of different types and some may have more of an impact on predicting the output than others. Genetic algorithms use a "fitness" measure to determine which of the individuals in the population survive and reproduce. Thus, survival of the fittest causes good solutions to evolve. The fitness for GRNN is the mean squared error of the outputs over the entire test set. 


\subsubsection{Training}

After preparing the input file and choosing the appropriate architecture to perform the task, training procedures are applied. In supervised learning, a set of input data and correct output data (targets) is used to train the network. The network, by use of the training input, produces its own output. This output is compared with targets, and the differences are used to modify the weights and biases. The procedures for modifying the weights and biases of a network are called learning rules. A test set (inputs and targets not used in training the network) is used to verify the quality of the Neural Networks and how well it can generalize [6]. Although the specific training of a given network depends on its architecture, most nets undergo a training process similar to that of a Backpropagation model.

In this study, two architectures were recommended by the NeuroShell 2 software to perform the task. The two architectures are back-propagation and general regression networks. Back-propagation networks are known for their prediction capabilities and ability to generalize well on a wide variety of problems. However, GRNN applications are able to produce continuous valued outputs. GRNN can responds much better than back-propagation to many types of problem [6]. The following parts discuss the process of training a network by both architectures. 


\section{- Training a network by Back-propagation}

1. The Feedforward of the Input Training Pattern:

In the first stage, all weights associated to the connection links are initialized and information is provided to the network via the input layer. Input data is multiplied by those weights. The sum of the product of all input neurons and their corresponding weights are then transmitted toward each middle neuron. Each of these middle neurons executes a simple computation by mapping the sum to output signal using its own activation function. The result is again multiplied by the weights of the connection links between each middle and output neuron. Output neurons calculate the sum of their weighted inputs to determine the final network output. At his point, each output unit compares its computed value with its target output, to determine the associated error for that pattern with that unit, which initiates the second stage of the training.

2. The Calculation and Backpropagation of the Associated Error:

Based on the associated error, a correction factor $\left(\mathrm{CF}_{1}\right)$ is calculated using the generalized delta rule. This correction factor helps to distribute the error from each output neuron back to all middle neurons that are connected to it. Similarly, another correction factor $\left(\mathrm{CF}_{2}\right)$ is computed for each middle neuron to propagate the error back to the neurons in the input layer. 
3. The Adjustment of the Weights:

After all of the correction factors have been determined, the weights for all layers are adjusted simultaneously. The adjustment for each weight is a function of the correspondent correction factor and the activation function of the previous neuron. That is, the adjustment of the weights of the connection links between the input and middle layer depends on $\mathrm{CF}_{2}$ and the activation function of the input neurons. Whereas weights of the connection links between the middle and output layer are altered based on $\mathrm{CF}_{1}$ and the activation function of the middle neurons, see Figure 5.

Figure 5 Training of an ANN by Backpropagation

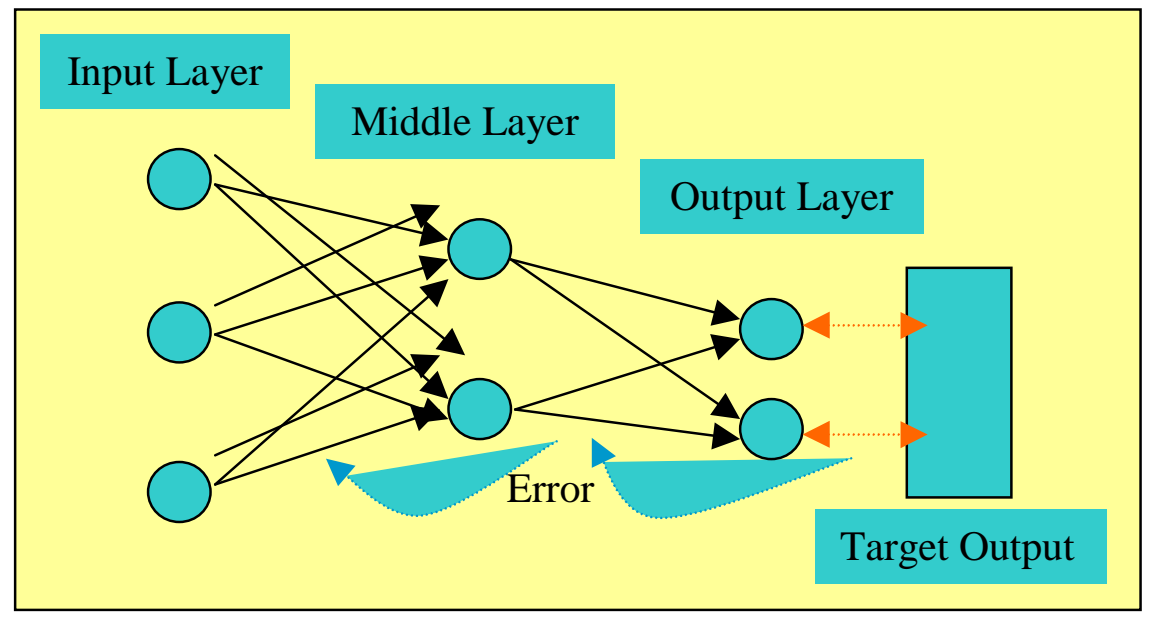


When training a net by Backpropagation, there are several parameters that must be set before training actually begins. Two of the most important settings are the Learning Rate and Momentum. These two parameters work together and help to define how fast and how stable the learning process is.

Each time a pattern is presented to the network, the weights leading to an output neuron are modified slightly during learning in the direction required to produce a smaller error the next time the same pattern is presented. Learning Rate controls the amount of modification in weights leading toward a smaller error.

\section{- Training a network by General Regression:}

General Regression Neural Networks are known for the ability to train quickly on sparse data sets. GRNN is a type of supervised network. In this study it was found that GRNN responded much better than Backpropagation. GRNN work by measuring how far given samples pattern is from patterns in the training set. The output that is predicted by the network is a proportional amount of all the output in the training set. The proportion is based upon how far the new pattern is from the given patterns in the training set. Some of the major GRNN training criteria are illustrated in the following sections.

1. Distance Metric:

GRNN networks work by comparing patterns based upon their distance from each other. There are two methods to compute this distance

a. Vanilla or Euclidean distance metric is recommended for most networks because it works the best. 
b. The City Block distance metric is the sum of the absolute values of the differences in all dimensions between the pattern and the weight vector for the neuron. City block distance is computed faster than Vanilla distance, but is usually not as accurate.

\section{Calibration}

If you have a test set for a GRNN network, you will probably want to use Calibration to decide which smoothing factor is best for your problem. The success of GRNN network is dependent upon the smoothing factor. There are three options for implementing Calibration for GRNN networks:

a. Iterative: With Calibration, training for GRNN networks proceeds in two parts. The first part trains the network with the data in the training set. The second part uses Calibration to test a whole range of smoothing factors, trying to hone on one that works best for the network created in the first part. Training is faster than when using the genetic adaptive option. You may want to use the iterative option when all of the input variables have the same impact on predicting the output. In general, it is recommended that you allow the network to choose a smoothing factor via Calibration. Remember, however, that the smoothing factor is only as good as the test set.

b. Genetic adaptive: Uses a genetic algorithm to find appropriate individual smoothing factors for each input as well as an overall smoothing factor. The input smoothing factor is an adjustment used to modify the overall smoothing factor to provide a new value for each input. Training takes longer than when 
using the iterative option. At the end of training, the individual smoothing factors may be used as a sensitivity analysis tool: the larger the factor for a given input, the more important that input to the model at least as far as the test set is concerned. You may want to use the genetic adaptive option when the input variables are of different types and some may have more of an impact on predicting the output than others. Genetic algorithms use a "fitness" measure to determine which of the individuals in the population survive and reproduce. Thus, survival of the fittest causes good solutions to evolve. The fitness for GRNN is the mean squared error of the outputs over the entire test set.

c. None: Simply trains the network but does not use Calibration to find an overall smoothing factor. When using the Apply module, a default value for the smoothing factor is displayed. The user will have to manually adjust the smoothing factor by entering a new one in the edit box.

\subsubsection{Verification}

There are various ways of looking at a neural network. The most common application is a pattern recognition tool where from a given amount of known information, a neural network can be trained to recognize some patterns [7], [8]. However, in order to achieve such results, a balance between memorization and generalization must be reached. 
To reach this goal, two sets of data are used during training, which are completely separate: a set of training patterns and set of training-testing patterns. Weight adjustments are based on the training patterns, however, at intervals during training, the error is computed using the test set. As long as the error on the test set decreases, training continues and the net is saved on the best performance on the test set. When the error begins to increase, the net starts to memorize the training patterns too specifically and starts to lose its ability to generalize as well. At this point, training is should be concluded.

\section{Figure 6 assuring good generalization of ANN}

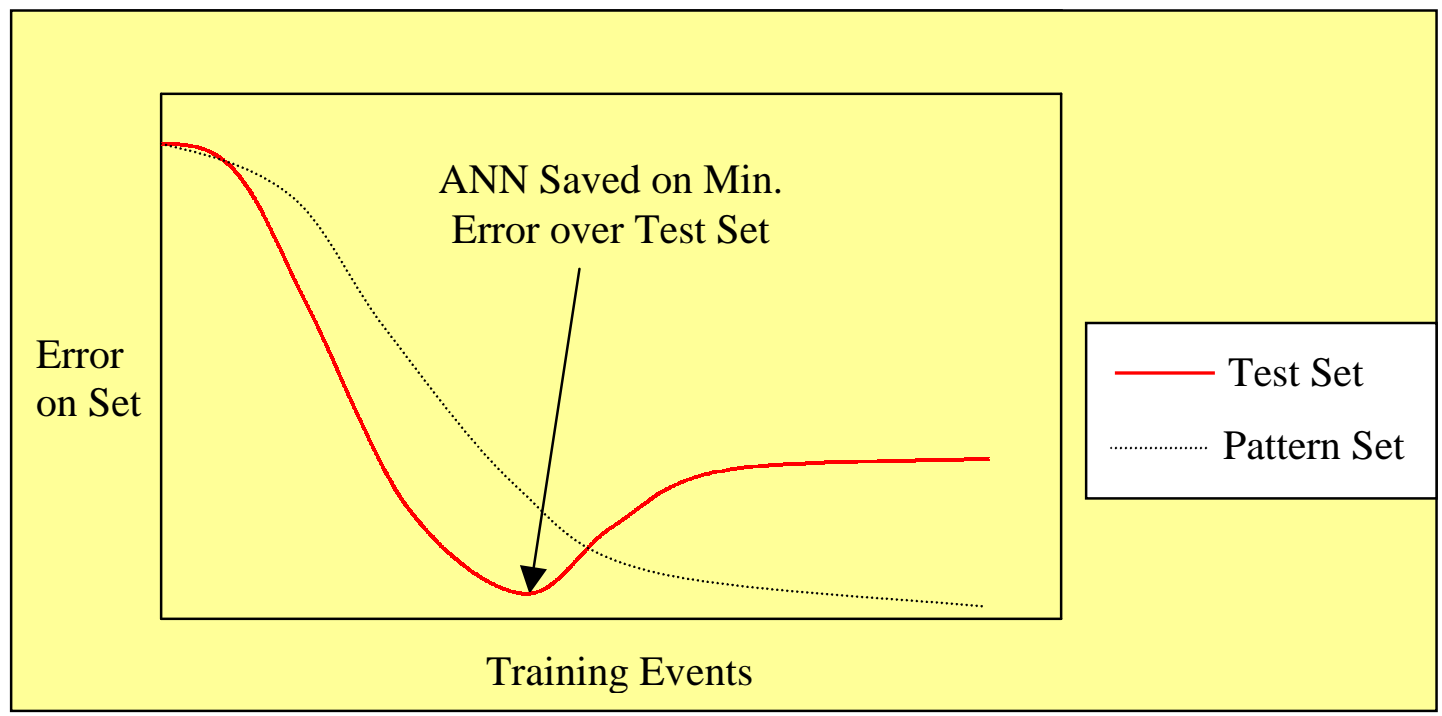

Calibration is another useful parameter when training a net, since it defines how often the test set is evaluated, thus optimizing the network's generalization. Other way to verify the network's predictions is by using a third data set called the production set, 
which is not used in the training process of the net. In this study, verification by use of production set was only performed by GRNN.

The production set contains similar data to that of the training and test patterns, that is, a set of inputs describing features as well as its correspondent target outputs. This data set is rather utilized to compare the predictions of the network with the actual target values by exposing the net developed to that set. 


\section{CHAPTER 3}

\section{METHODOLOGY}

The work presented here is a part of complex project, which is intended to evaluate the Stringtown Oil Reservoir. The methodology used in this study takes advantage of the Neural Network to predict porosity with acceptable accuracy. The approach used in this study is described in the following sections.

\subsection{Objectives}

Characterizing a reservoir is a very complex task, due to heterogeneity. Heterogeneous reservoirs are known for the large changes in their properties within small area. Distinct geological ages, nature of rock, depositional environments are some of the reasons behind the heterogeneity of a formation. Reservoir characterization plays an important role in the petroleum industry, particularly, to the economic success of the reservoir development method.

The purpose of this study is to develop a neural network model that can be used to predict porosity values throughout the reservoir. Using Gamma Ray (GR) and Bulk Density (RHOB) which are available from most wells in the field, the geophysical logs from over 120 wells were used to map porosity distribution throughout the entire reservoir. 
Porosity from bulk density logs is based on the assumptions, where we considered the formation to be of Limy Sandstone with matrix density $\rho m$ of $2.68 \mathrm{gr} / \mathrm{cc}$. Also, fluid density of water $\rho f$ was assumed as $1.0 \mathrm{gr} / \mathrm{cc}$. However, porosity predicted using neural network is not based on any of these assumptions.

There are many reasons for the superiority of artificial neural networks prediction. However, variables such as Gamma Ray, x coordinate, y coordinate can be very important factors that can be added to obtain a reliable porosity prediction. These variables can provide valuable information to the network.

\subsection{Data Collection}

For the purpose of this study, core data were collected from seven wells in the field. The wells selected were the following: well 095-0741, well 095-0859, well 0951124, well 095-1125, well 095-1126, well 103-1315 and well 103-1547. Two wells (well 095-0741 and well 095-0859) are located in the dual five-spot waterflood pilot area. Table 2 shows the cored wells in the field. Geophysical logs are available from most of the wells in the field, if not all. We collected the geophysical logs from over 120 wells strategically distributed on the field. A total of 296 core and log porosity data were collected to develop the network. 


\section{Table 2 Cored Wells Information}

\begin{tabular}{|c|c|c|c|c|}
\hline Well & Core Date & Core Interval & Analysis Performed & Digitized Logs \\
\hline $47-095-741$ & 14-Dec-79 & $\begin{array}{c}2889.6-2909.8 \\
=20.2 \mathrm{ft}\end{array}$ & $\begin{array}{c}\text { Horizontal Plug Perm. } \\
\text { (kmax vs. He\% Por.) } \\
\text { Full Diameter } \\
\text { (kmax,k90,kver. Vs. } \\
\text { He\% Por and Grain } \\
\text { Density) }\end{array}$ & RHOB, GR \\
\hline $47-095-859$ & 04-Dec-80 & $\begin{array}{c}3083.4-3101.0 \\
=17.6 \mathrm{ft}\end{array}$ & $\begin{array}{c}\text { Conventional Plug } \\
\text { Type (k90 vs. He\% } \\
\text { Por. And Grain } \\
\text { Density) }\end{array}$ & RHOB, GR \\
\hline $47-095-1124$ & 24-Jan-86 & $\begin{array}{c}2779.0-2799.0 \\
=20 \mathrm{ft}\end{array}$ & $\begin{array}{l}\text { Conventional Plug (k } \\
\text { and kver vs. He\% Por., } \\
\text { So and Sw) }\end{array}$ & $\begin{array}{l}\text { RHOB, GR, } \\
\text { Neutron }\end{array}$ \\
\hline $47-095-1125$ & 24-Jan-86 & $\begin{array}{c}2988.5-3015.0 \\
=26.5 \mathrm{ft}\end{array}$ & $\begin{array}{l}\text { Conventional Plug (k } \\
\text { and kver and k90 vs. } \\
\text { He\% Por and Grain } \\
\text { Density) }\end{array}$ & $\begin{array}{l}\text { RHOB, GR, } \\
\text { Neutron }\end{array}$ \\
\hline $47-095-1126$ & 26-Dec-85 & $\begin{array}{c}3086.0-3115.0 \\
=29.0 \mathrm{ft}\end{array}$ & $\begin{array}{l}\text { Conventional Plug (k } \\
\text { and kver vs. He\% Por., } \\
\text { So and Sw }\end{array}$ & $\begin{array}{l}\text { RHOB, GR, } \\
\text { Neutron }\end{array}$ \\
\hline $47-103-1315$ & 27-Dec-84 & $\begin{array}{c}2880.7-2896.5 \\
=15.8 \mathrm{ft}\end{array}$ & $\begin{array}{l}\text { Plug Perm. (k90 vs. } \\
\text { He\% Por.) Full } \\
\text { Diameter } \\
\text { (kmax,k90,kver vs. } \\
\text { He\% Por, Grain } \\
\text { Density, So and Sw) }\end{array}$ & RHOB, GR \\
\hline $47-103-1547$ & 08-Oct-93 & $\begin{array}{c}3032.4-3061.5 \\
=29.1 \mathrm{ft}\end{array}$ & $\begin{array}{l}\text { Conventional Plug (k } \\
\text { vs. He\% Por. And } \\
\text { Grain Density) }\end{array}$ & $\begin{array}{l}\text { RHOB, GR, } \\
\text { Neutron }\end{array}$ \\
\hline $47-095-1149$ & 01-Jun-92 & $\begin{array}{c}2865.0-2876.0 \\
=11 \mathrm{ft}\end{array}$ & $\begin{array}{l}\text { Conventional Plug (k } \\
\text { and kver vs. He\% Por., } \\
\text { So and } \mathrm{Sw})\end{array}$ & GR \\
\hline $47-103-1695$ & 18-Jun-96 & $\begin{array}{c}2889.5-2903.7 \\
=14.2 \mathrm{ft}\end{array}$ & $\begin{array}{l}\text { Rotary Side Core } \\
\text { Analysis (kair vs. } \\
\text { He\% Por. And Grain } \\
\text { Density) }\end{array}$ & - \\
\hline
\end{tabular}




\subsection{Data Analysis}

It is necessary to integrate the geological descriptions of the various zones, in order to define the zones quantitatively so that a correlation can be developed [9]. Core Porosity-Log Porosity correlation began with the determination of the pay zone and digitization of Density and Gamma Ray Logs. Determination of the productive zones in every well and finding a similarity between the variables involved is very important to establish a reliable correlation.

A comparison was made between core porosity and log porosity (derived from density $\log$ ) for a given depth. Porosity determination derived from the density log shows a good agreement with core-determined porosity. The zone matrix was assumed to be Limy Sandstone with a density $\left(\rho_{\mathrm{m}}\right)$ of $2.68 \mathrm{gr} . / \mathrm{cc}$ and the fluid as water $\left(\rho_{\mathrm{f}}=1 \mathrm{gr} . / \mathrm{cc}\right)$, thus $\log$ porosity $\left(\phi_{1}\right)$ was derived as:

$$
\phi_{l}=\frac{\left(\rho_{m}-\rho_{b}\right)}{\left(\rho_{m}-\rho_{f}\right)} * 100
$$

Where: $\phi_{l}=\log$ Porosity [\%]

$$
\begin{aligned}
& \rho_{m}=\text { Matrix Density }[\mathrm{gr} / \mathrm{cc}] \\
& \rho_{b}=\text { Bulk Density }[\mathrm{gr} / \mathrm{cc}] \\
& \rho_{f}=\text { Fluid Density }[\mathrm{gr} / \mathrm{cc}]
\end{aligned}
$$


Most of the core plugs are taken at every foot of the formation, through the well, while the digitized logs data were taken at every three inches, so that there would be four $\log$ data points per one foot interval. Care was taken to match the depth of core and $\log$ in order to make as accurate correlation as possible. The depth correction varied from 0.1 $\mathrm{ft}$ to $2.0 \mathrm{ft}$. Table 3 shows the average depth shifting applied to each of the cored wells for porosity correlation

Table 3: Average Core Depth Shifting

\begin{tabular}{|c|c|c|}
\hline Well & $\begin{array}{c}\text { Core Depth Shifting } \\
\text { (ft) }\end{array}$ & Direction \\
\hline $\mathbf{0 9 5 - 0 7 4 1}$ & 0.12 & Downward \\
$\mathbf{0 9 5 - 0 8 5 9}$ & 0.10 & Upward \\
$\mathbf{0 9 5 - 1 1 2 4}$ & 0.90 & Downward \\
$\mathbf{0 9 5 - 1 1 2 5}$ & 1.50 & Upward \\
$\mathbf{0 9 5 - 1 1 2 6}$ & 0.70 & Upward \\
$\mathbf{1 0 3 - 1 3 1 5}$ & 0.40 & Downward \\
$\mathbf{1 0 3 - 1 5 4 7}$ & 2.00 & Upward \\
\hline
\end{tabular}

The comparison of the measured porosity values using helium porosimeter for core plugs and the porosity values derived from density log suggested the need for some adjustment in core depths to overcome the inherent inadequacies in coring and core handling techniques [9], [10], [11]. In other words, the core depths were shifted up or down to provide a good match with log porosity values. More over, some points were adjusted independently to correspond better to log porosity trends.

Log porosity and core porosity values were plotted versus depth for each selected well with core. Thus, one correlation plot was prepared for all the selected wells for this study. Figure 7 shows the porosity correlation for well 095-1125. Porosity correlation graphs for the rest of the cored wells in the field are given in Appendix I. 
Figure 7 Core Porosity vs. Log Porosity for Well 095-1125

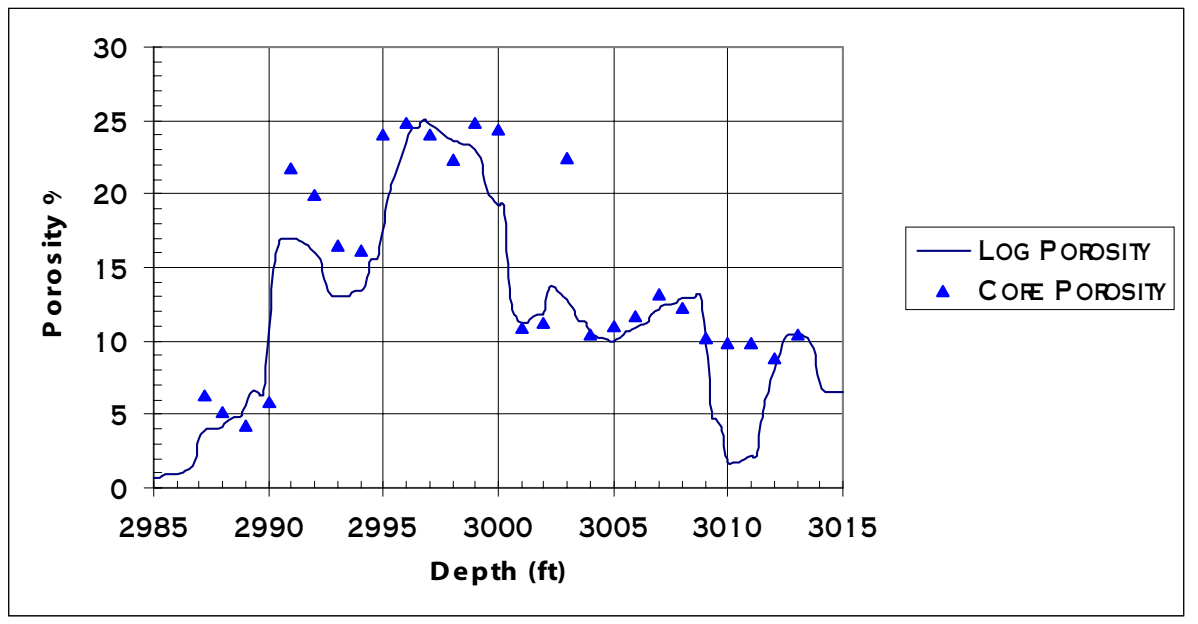

Even though core porosity values are not exactly the same as porosity values determined from logs, the important point here is that porosity trends follow the same profile at a given depth interval in the pay zone. A correlation between core porosity and $\log$ porosity was found to be acceptable for all wells except for well 103-1315, which shows very low correlation, however this well has a very thin pay zone.

Once all of the wells were correlated using core and log porosity, the second step was to plot core porosity and log responses (RHOB and GR) versus depth to observe any similarity or relationships among them. Figure 8 shows a plot of porosity versus log responses (Bulk Density and Gamma Ray) for well 095-1124, Appendix II contains plots for the rest of cored-wells. 
Figure 8 Porosity and Log responses vs. Depth for Well 095-1124

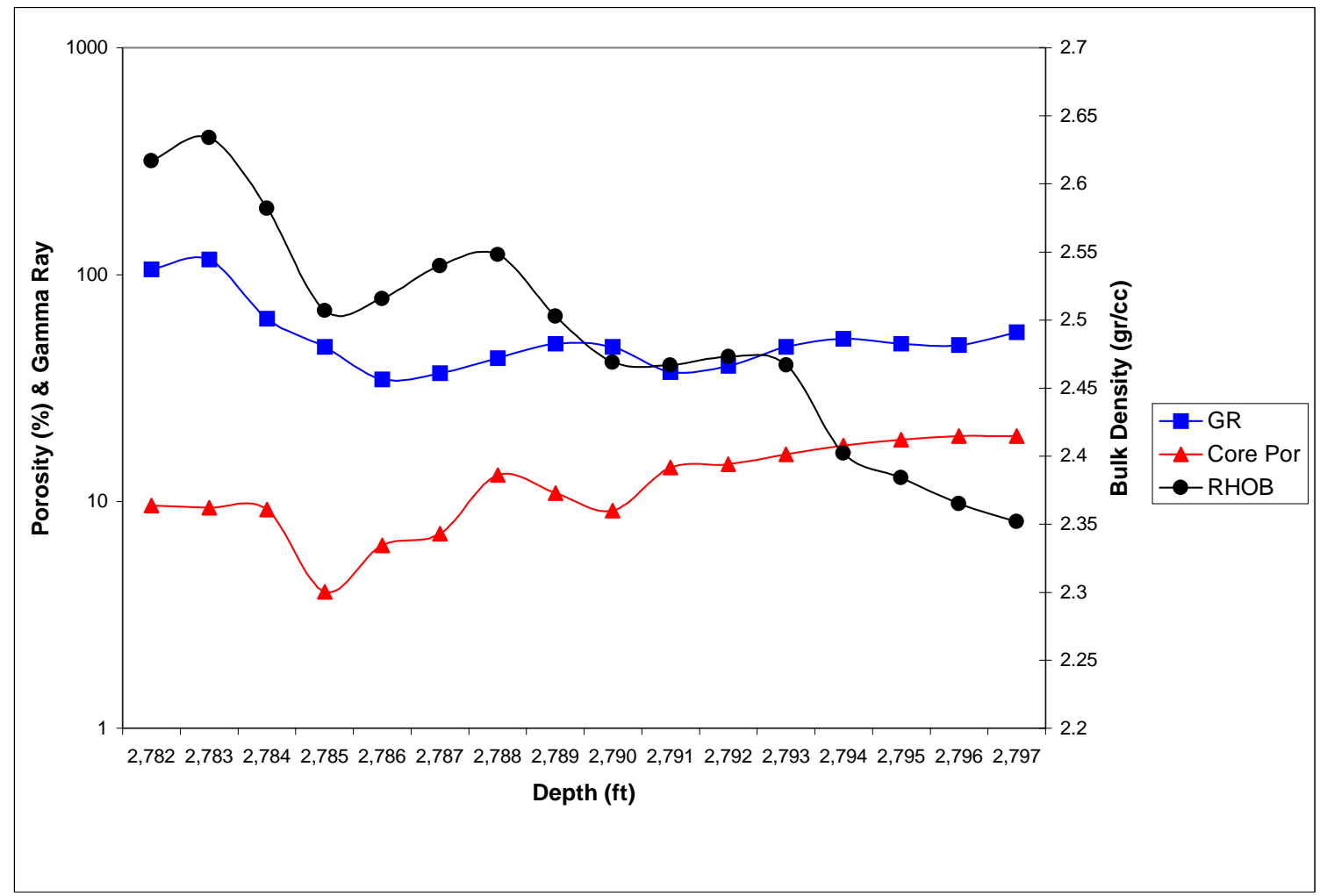

In the development of these plots, a cut-off in porosity of $1.0 \%$ was considered, which is a very low porosity but it was considered for illustration purposes only.

\subsection{Input Selection}

The fundamental assumption in this study is that geophysical log data contain information about formation porosity. There is a clear relationship between porosity and bulk density, however relation of Gamma Ray Log data with porosity is not direct and explicit. The objective of this study is to evaluate porosity values from log data without any assumptions. 
The first and logical selection as input data was log responses (Bulk Density, RHOB, and Gamma Ray, GR). RHOB log responses are a measure of the formation porosity. GR logs are an indication of the clay content and shaliness of the rock. Although, there were other logs available in the reservoir such as neutron porosity and induction logs, the choice of the particular set of logs (GR and RHOB) was primarily dictated by their availability in the majority of the wells in the Stringtown field.

The second set of input data consists of the well coordinates and depths intervals for that well. This data set defines a point in space. The third set of data is the first derivatives of the log responses, which, provide a significant information to the neural network about the rate of change in the log responses. The first derivatives of $\log$ responses were computed using the three-point method, which considers that the value of the derivative at a given point is a function of the weighted average of the previous and next slopes relative to that point, see Figure 9.

Figure 9 Derivative Calculation using the Three-Point Method

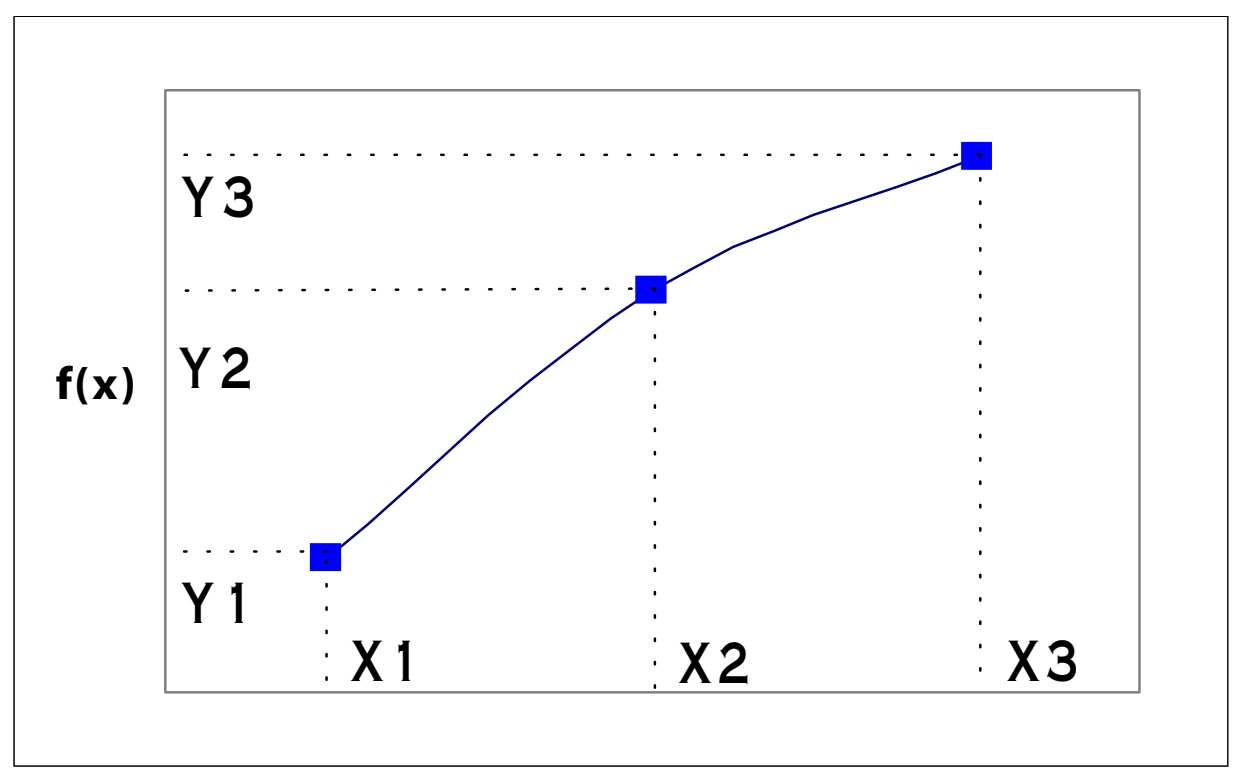


According to the fore statement, the value of the derivative at point $2, \mathrm{~m}_{2}$, is:

$$
\begin{aligned}
& m_{l}=\frac{y_{2}-y_{1}}{x_{2}-x_{1}} \\
& m_{r}=\frac{y_{3}-y_{2}}{x_{3}-x_{2}} \\
& m_{2}=\frac{\left(x_{3}-x_{2}\right) m_{l}+\left(x_{2}-x_{1}\right) m_{r}}{\left(x_{3}-x_{2}\right)+\left(x_{2}-x_{1}\right)}
\end{aligned}
$$

In summary, the input data selected to train the ANN consisted of seven features: RHOB and GR log values, well coordinates and depth and the first derivatives of the log responses. Of course, the input data set also featured the correspondent values of core plug porosity as target outputs of the supplied log.

\subsection{Artificial Neural Network Training}

The training of the selected artificial neural network was conducted using a total of 148 pattern data points from the cored wells. The following paragraphs discuss the training process for the selected nets:

- Training the Network by Backpropagation:

Since the problem was very complex and noisy, the learning rate and momentum were set at 0.1 . The pattern data set was split in a training set and a test set. The test set was chosen as $20 \%$ of the pattern set and the data points conforming it were randomly selected. 
The values to initialize the weights on all connection links were set at 0.3 and the calibration interval at 200 learning events. The criterion to stop training was set when the number of training events reached 20,000 after a minimum error on the test set was computed. To compare the network predictions versus actual core plug porosity data; a plot of these two values versus depth was made for each of the cored wells used during training. See Figure 10 for well 095-0741

Figure 10 Predictions by Back-Propagation vs. Actual Core Porosity

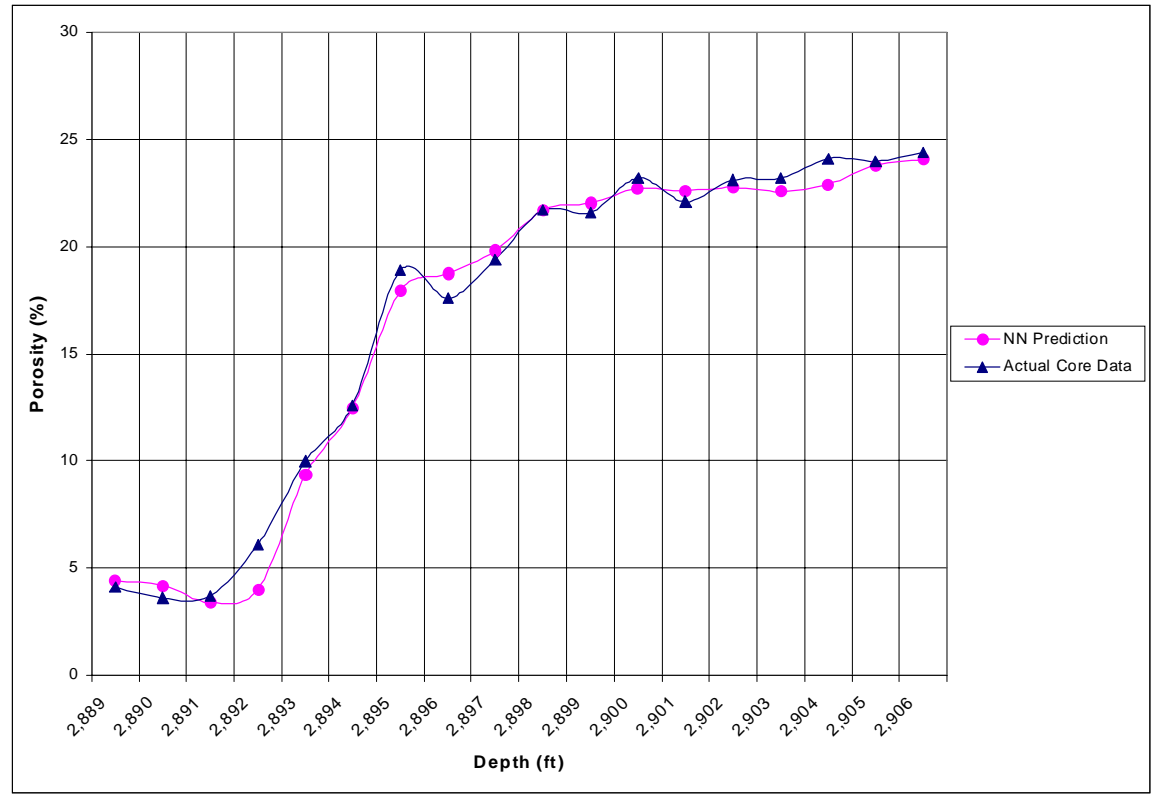


Table 4 Input Strength for Back-propagation

\begin{tabular}{|c|c|}
\hline Input Variable & Input Strength \\
\hline RHOB Log & 28.42 \\
Depth & 15.43 \\
Y Coordinate & 13.93 \\
GR & 11.82 \\
X Coordinate & 11.65 \\
GR Log $\mathbf{1}^{\text {st }}$ Derivative & 9.95 \\
RHOB Log 1 $^{\text {st }}$ Derivative & 8.80 \\
Total & 100 \\
\hline
\end{tabular}

The strength of the input variables to predict porosity is given by their degree of contribution to the output layer, which is determined by the weights of the connection links between layers. On a percentile scale, contribution factors are shown in Table 4. We can observe that the most important variable to the ANN is the RHOB.

Depth, y coordinates, GR, and $\mathrm{x}$ coordinates also play significant roles in the model. The weakest variables are the log first derivatives. However this does not mean that they may be taken out of the model, as we experienced, $\mathrm{R}^{2}$ ratio was lower before we add the first derivatives of $\log$ responses. Even though, the first derivatives of $\log$ responses are the weakest contributing factors to the net, they play a significant role in the overall prediction of porosity. 
- $\quad$ Training The Network by GRNN:

GRNN is essentially trained after one pass of the training patterns, and it is capable of functioning after only a few training patterns have been entered. Obviously, GRNN training improves as more patterns are added. We trained the network with the genetic adaptive option. After training begins when the user selects the run menu, individual smoothing factors for each of the input variables are displayed. The input smoothing factor is an adjustment used to modify the overall smoothing to provide a new value for each input. At the end of training, the individual smoothing factors may be used as a sensitivity analysis tool. The predictions of GRNN with $\mathrm{R}^{2}$ of 0.97 outperform the predictions of Back-Propagation with $\mathrm{R}^{2}$ of 0.92 . To compare the network predictions versus actual core plug porosity data; a plot of these two values versus depth were made for each of the cored wells used in training. See Figure 11 for well 095-0741

\section{Figure 11 Predictions by GRNN vs. Actual Core Porosity}

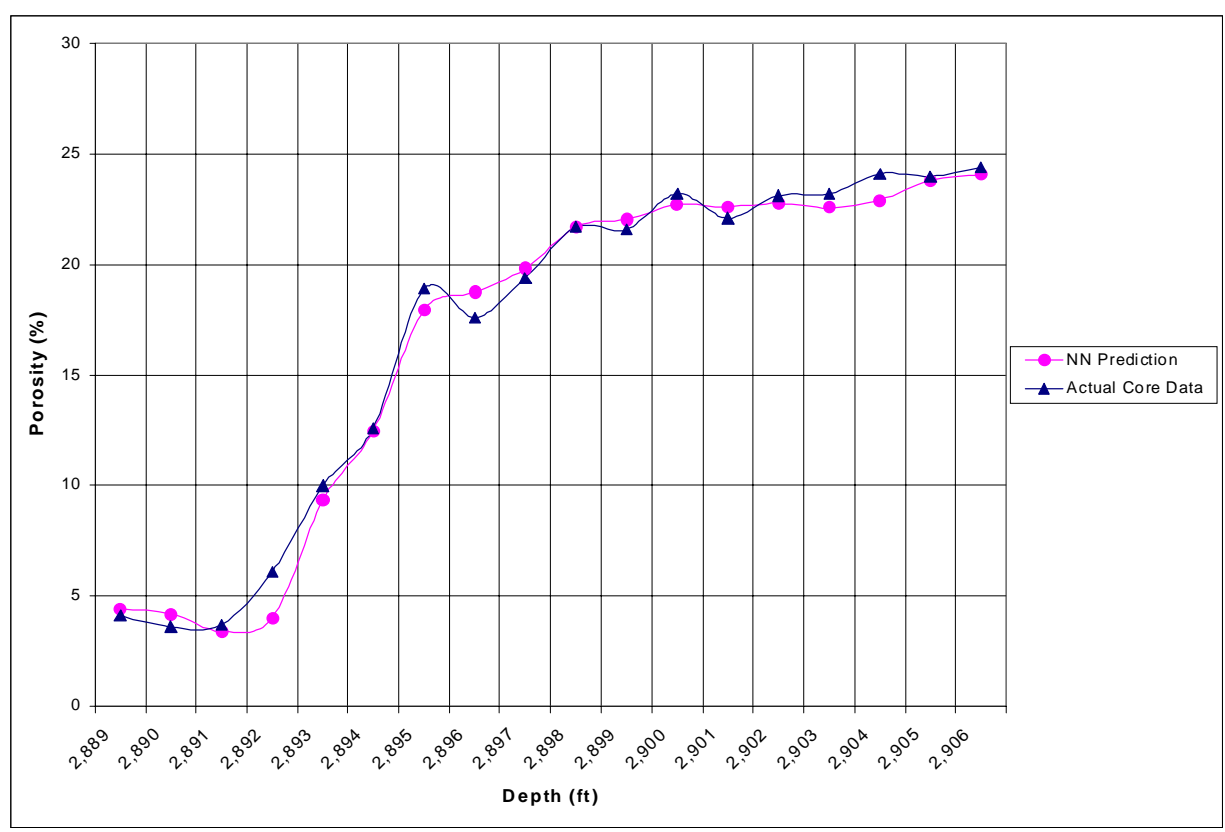


Figure 12 Correlation of Actual Core Porosity and GRNN Predictions in the

\section{Test Set}

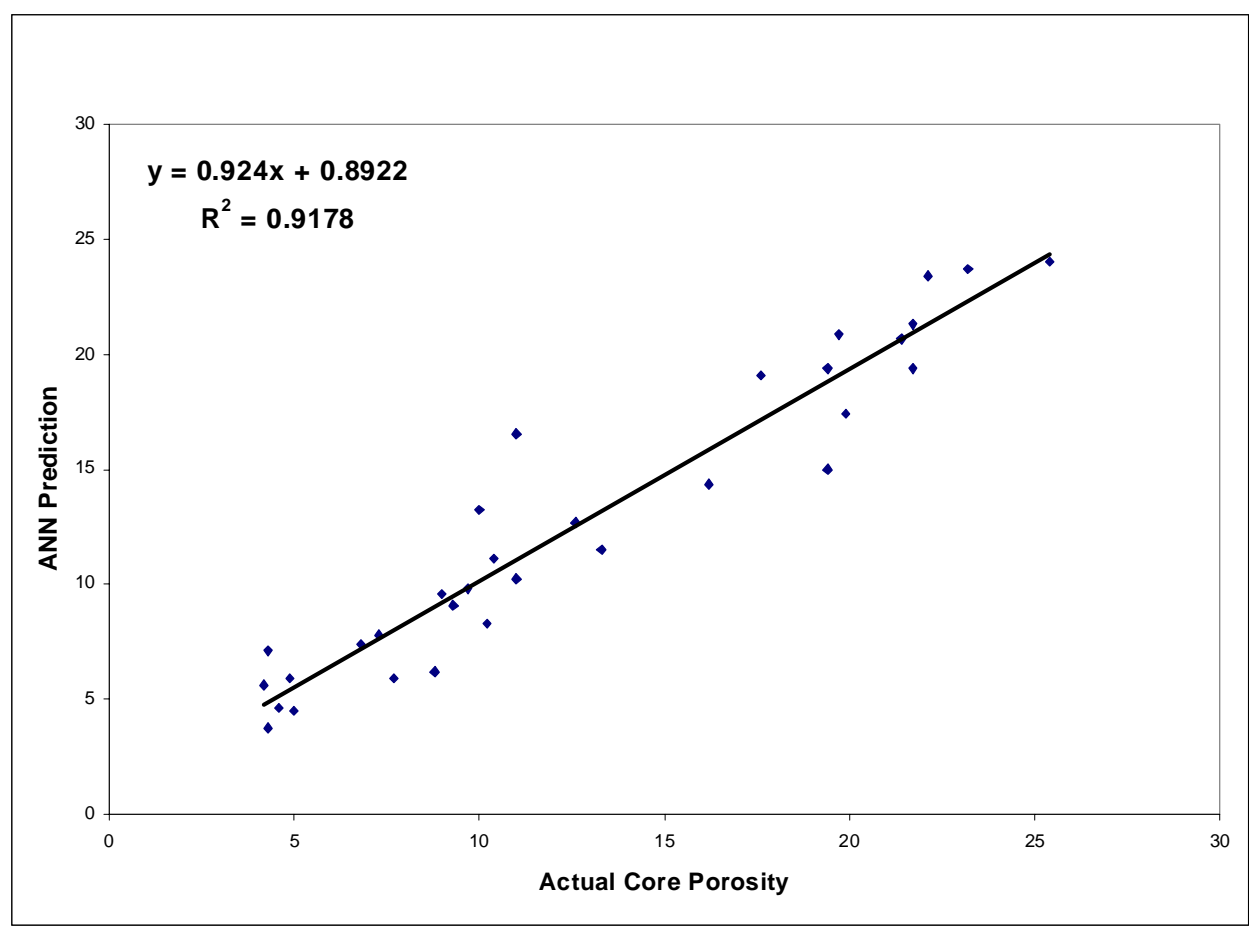

\subsection{Artificial Neural Network Verification}

Back-propagation models are known by their ability to generalize well on data that they have never seen due to the use of test sets during training. However, we selected GRNN to verify the ANN model and its predictions by means of production sets.

A production set consists in one input data set, which was not used during training. Thus, the verification of ANN predictions and core porosity values was made by developing several similar networks. At first, we put one cored well aside during training and exposing the net to the input data set for the rest of the wells. Then, we compared the net prediction against the actual core porosity for the well that was put aside. 
The previous procedures were repeated for the rest of the wells, where in each run a different well was put aside to ensure the robustness of this method. Using only the seventh well 's log data a porosity profile can be predicted. The predicted porosity profile was compared with the actual laboratory measurements of the porosity for the selected well [3]. The results of this process are shown in Table 5.

Table 5 GRNN Production Sets Results

\begin{tabular}{|c|c|c|c|c|c|}
\hline $\begin{array}{c}\text { Well in } \\
\text { Production Set }\end{array}$ & $\begin{array}{c}\mathbf{R}^{\mathbf{2}} \\
\text { All Data }\end{array}$ & $\begin{array}{c}\mathbf{R}^{\mathbf{2}} \text { Excluding } \\
\text { Production Set }\end{array}$ & $\begin{array}{c}\text { Data in } \\
\text { Training set }\end{array}$ & $\begin{array}{c}\text { Data in Test } \\
\text { set }\end{array}$ & $\begin{array}{c}\text { Data in } \\
\text { Production set }\end{array}$ \\
\hline $\mathbf{0 9 5 - 0 7 4 1}$ & 0.838 & 0.841 & 104 & 26 & 18 \\
$\mathbf{0 9 5 - 0 8 5 9}$ & 0.914 & 0.917 & 108 & 27 & 13 \\
$\mathbf{0 9 5 - 1 1 2 4}$ & 0.906 & 0.932 & 106 & 26 & 16 \\
$\mathbf{0 9 5 - 1 1 2 5}$ & 0.914 & 0.917 & 97 & 24 & 27 \\
$\mathbf{0 9 5 - 1 1 2 6}$ & 0.935 & 0.979 & 96 & 23 & 29 \\
$\mathbf{1 0 3 - 1 3 1 5}$ & 0.887 & 0.915 & 107 & 26 & 15 \\
$\mathbf{1 0 3 - 1 5 4 7}$ & 0.894 & 0.908 & 95 & 23 & 30 \\
\hline
\end{tabular}

Neural Networks can predict porosity values for entire wells without prior exposure to their log or core data and with accuracy's that are unmatched by any other technique. The ability of ANN to learn from experience and then generalize these learning to solve new problems sets it a part from all conventional methods [3].

In all cases, the $\mathrm{R}^{2}$ coefficient computed when the ANN trained excluding the production set was higher than that calculated using the whole data set, meaning that the ANN learned well on the pattern set. Nevertheless, when computing the $\mathrm{R}^{2}$ coefficient for all of the data points, it is lower, but still acceptable since this value is higher than 0.838 . One of the factors affecting this situation is the fact that when production sets are used, the ANN trains on fewer points than the complete set, so it has to infer porosity values based on less knowledge. From here, a network in fact, several networks, could simulate 
the distribution of the porosity in the field with a correlation coefficient of 0.9. GRNN's predictions were closer to the core porosity measurements. Figure 13 is an example of the good prediction results obtained by this verification process by means of production set.

Figure 13 Porosity Profile based on GRNN forecast for Cored Well 095-1126

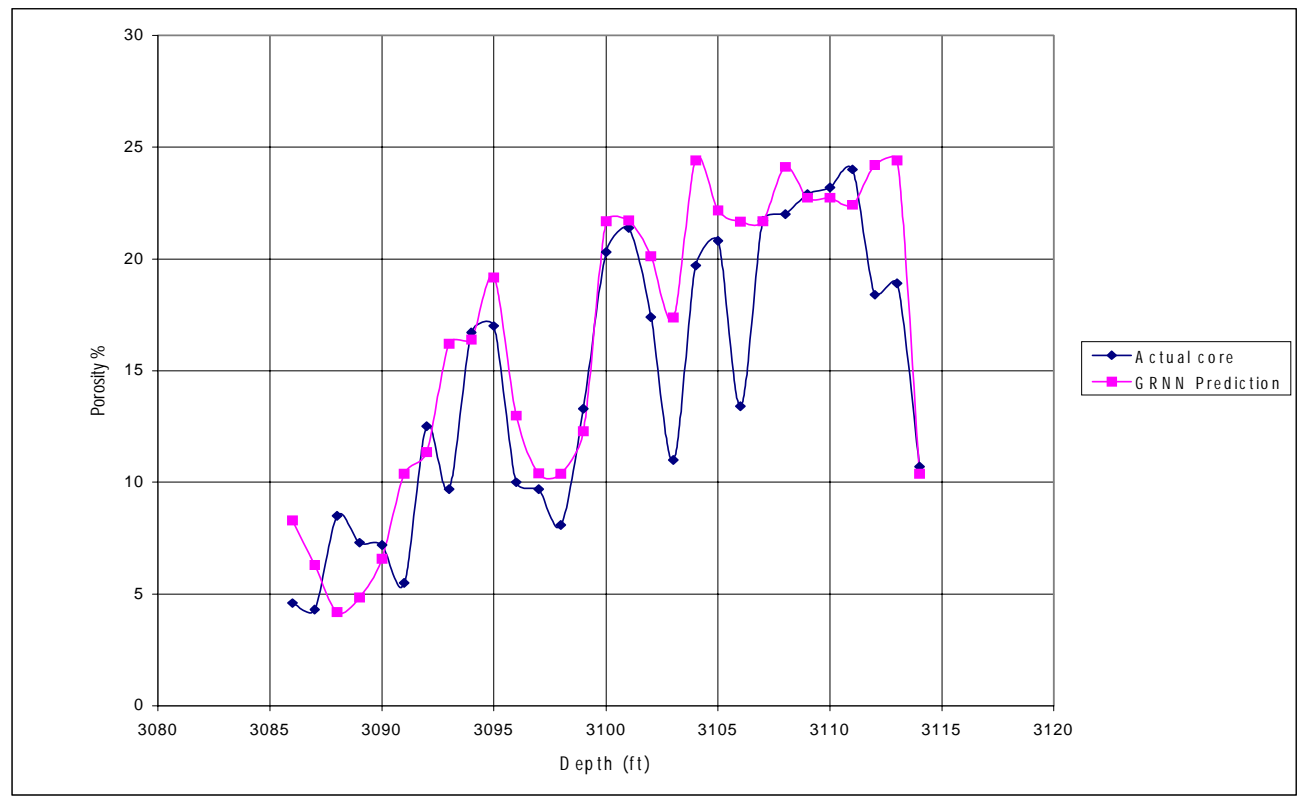

\subsection{Artificial Neural Network Prediction}

With these promising results, porosity was predicted for the rest of the uncored wells in the reservoir. As we mentioned earlier, the predictions of core porosity by GRNN were better than the one predicted by Back-Propagation. The results of the verification process by means of production set were promising. Table 6 shows the predicted $\mathrm{R}^{2}$ ratio of the various runs performed by Backpropagation and GRNN. 
Table 6 Prediction Results Comparison

\begin{tabular}{|c|c|c|}
\hline Run & Back-Propagation Network & GRNN \\
\hline Excluding Log Porosity & 0.93 & 0.89 \\
5 \% Cut Off of Porosity & 0.92 & 0.96 \\
Including RHOB and GR 1 $^{\text {st }}$ Derivatives & 0.88 & 0.97 \\
\hline
\end{tabular}

From Table 6, we can see that when we made a $5 \%$ cut off of porosity and when we included the bulk density and gamma ray logs to the input, core porosity predictions were higher for the General Regression Neural Network. However, in the case when we excluded log porosity from the input, the Back Propagation network predicts better results of core porosity. This explains the fact that both networks are known for their prediction capabilities. Figure 14 shows the correlation obtained by back-propagation network between ANN predictions versus log porosity with $\mathrm{R}^{2}$ of 0.917 . 
Figure 14 A Correlation between ANN Predictions vs. Log Porosity

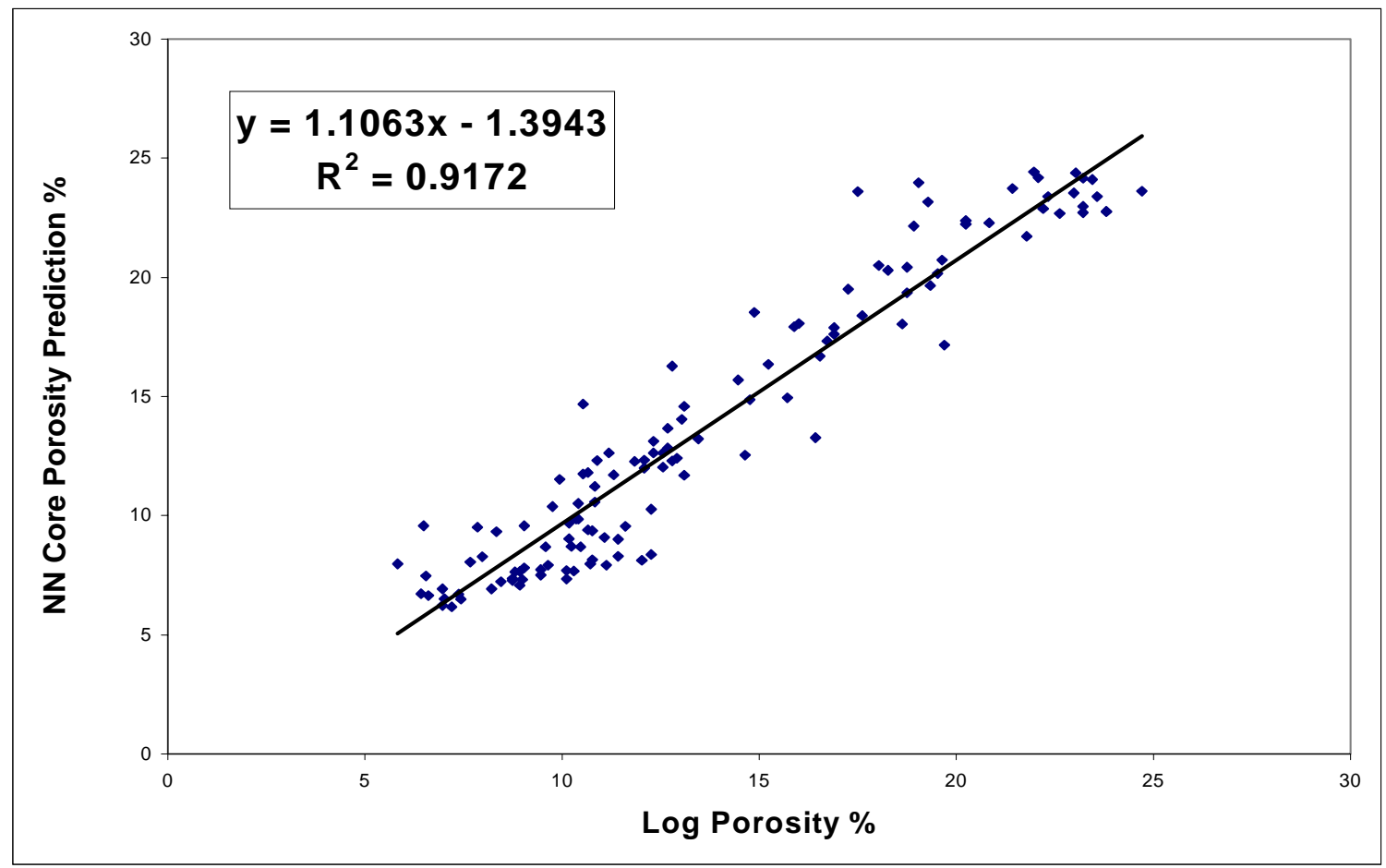




\section{CHAPTER 4}

\section{RESULTS AND DISSCUSSION}

Figure 15 shows the core porosity versus log porosity correlation for all wells using linear regression. The equation of the linear regression for all the wells is $\mathrm{y}=$ $0.998 x+0.3535$ with $R^{2}$ ratio being 0.8047

\section{Figure 15 Porosity Correlation for All Wells}

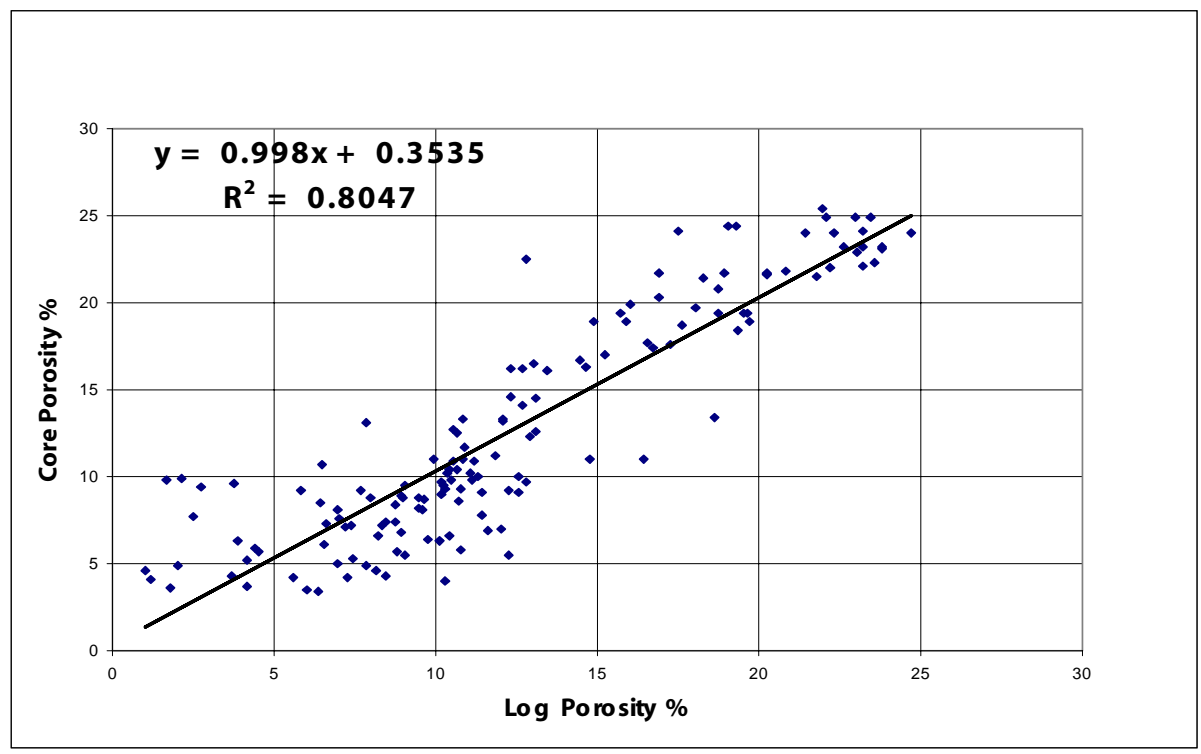

Among the factors that contribute to the fact that core and log porosity values are not the same are the heterogeneity of the formation, and the assumption that the matrix density is constant throughout the reservoir. Also, logging tools record values based on the average of the surroundings at a given point whereas core plug measurements reflect more details of that specific point. Based on the configuration set when developing the network, back-propagation supplied the following results. 
Table 7 Back-Propagation Network Statistical Results

\begin{tabular}{|c|c|}
\hline Output & $\begin{array}{c}\text { Core Plug } \\
\text { Porosity [\%] }\end{array}$ \\
\hline Patterns processed: & 148 \\
R squared: & 0.922 \\
r squared: & 0.9251 \\
Mean squared error: & 3.334 \\
Mean absolute error: & 1.358 \\
Min. absolute error: & 0.006 \\
Max. absolute error: & 5.359 \\
Correlation coefficient r: & 0.9618 \\
Percent within 5\%: & 35.135 \\
Percent within 5\% to 10\%: & 14.189 \\
Percent within 10\% to 20\%: & 22.973 \\
Percent within 20\% to 30\%: & 14.865 \\
Percent over 30\%: & 12.838 \\
\hline
\end{tabular}

The most important fact to notice in Table 7 is that the $\mathrm{R}^{2}$ coefficient is as high as 0.92 where 1.0 is a perfect match.

Figure 16 Correlation of Actual Core Porosity and Back-Propagation Predictions

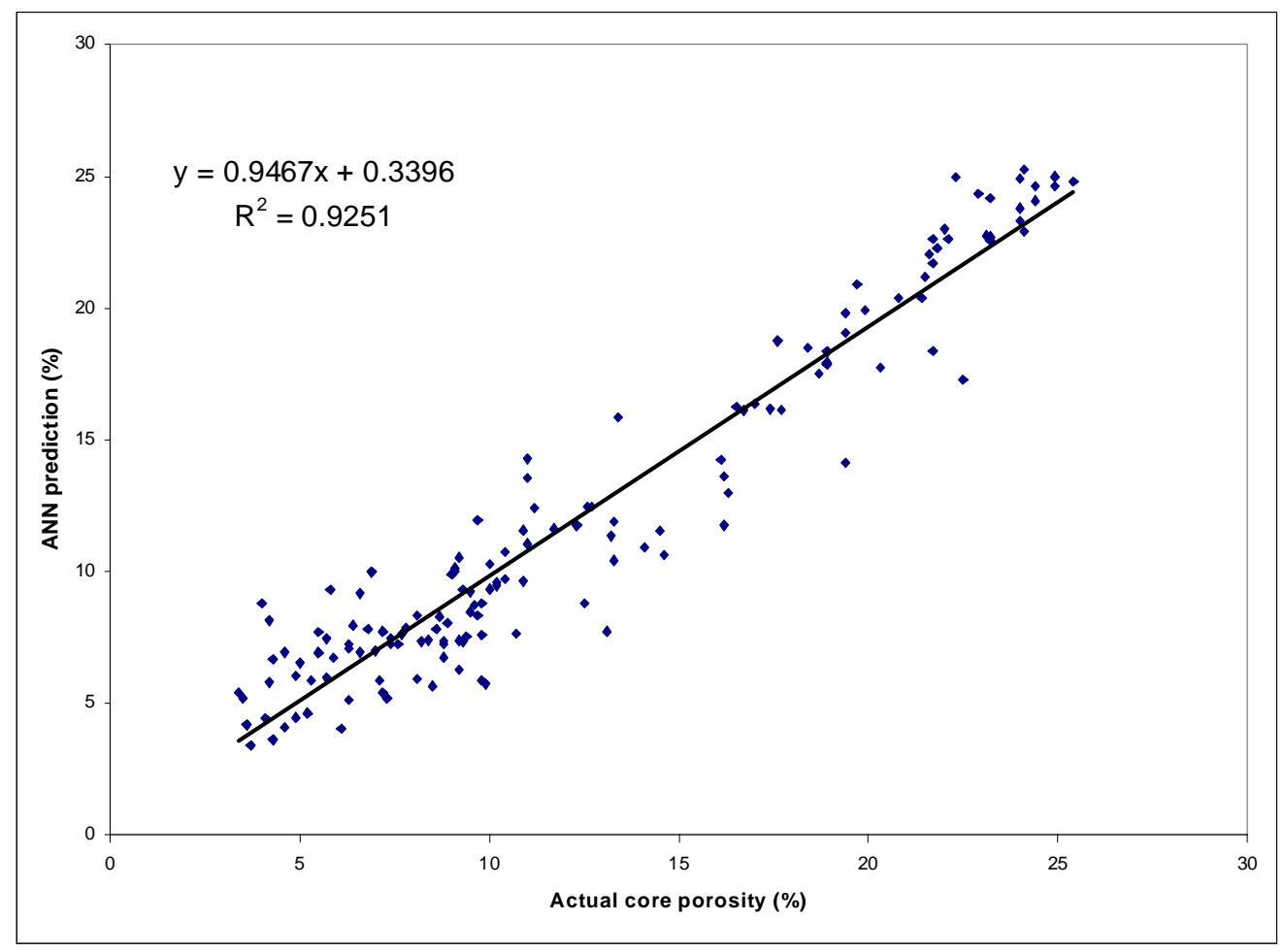




\section{Table 8 ANN Statistical Results}

\begin{tabular}{|c|c|}
\hline Network type: & GRNN, genetic adaptive \\
\hline Patterns processed: & 148 \\
Smoothing factor: & 0.10317647 \\
R squared: & 0.9668 \\
r squared: & 0.967 \\
Mean squared error: & 1.42 \\
Mean absolute error: & 0.741 \\
Min. absolute error: & 0 \\
Max. absolute error: & 5.717 \\
Correlation coefficient r: & 0.9833 \\
Percent within 5\%: & 55.405 \\
Percent within 5\% to 10\%: & 17.568 \\
Percent within 10\% to 20\%: & 13.514 \\
Percent within 20\% to 30\%: & 8.784 \\
Percent over 30\%: & 4.73 \\
\hline
\end{tabular}

The most important fact to notice in Table 8 is that the $\mathrm{R}^{2}$ coefficient is as high as 0.967 where 1.0 is a perfect match.

Using the powerful features of ANN, we were able to predict porosity for the uncored wells. The predicted porosity values for each well were averaged, using its depth interval. From here, porosity distribution was mapped throughout the field as shown in Figure 17. 
Figure 17 Porosity Distribution Map for the Stringtown Field

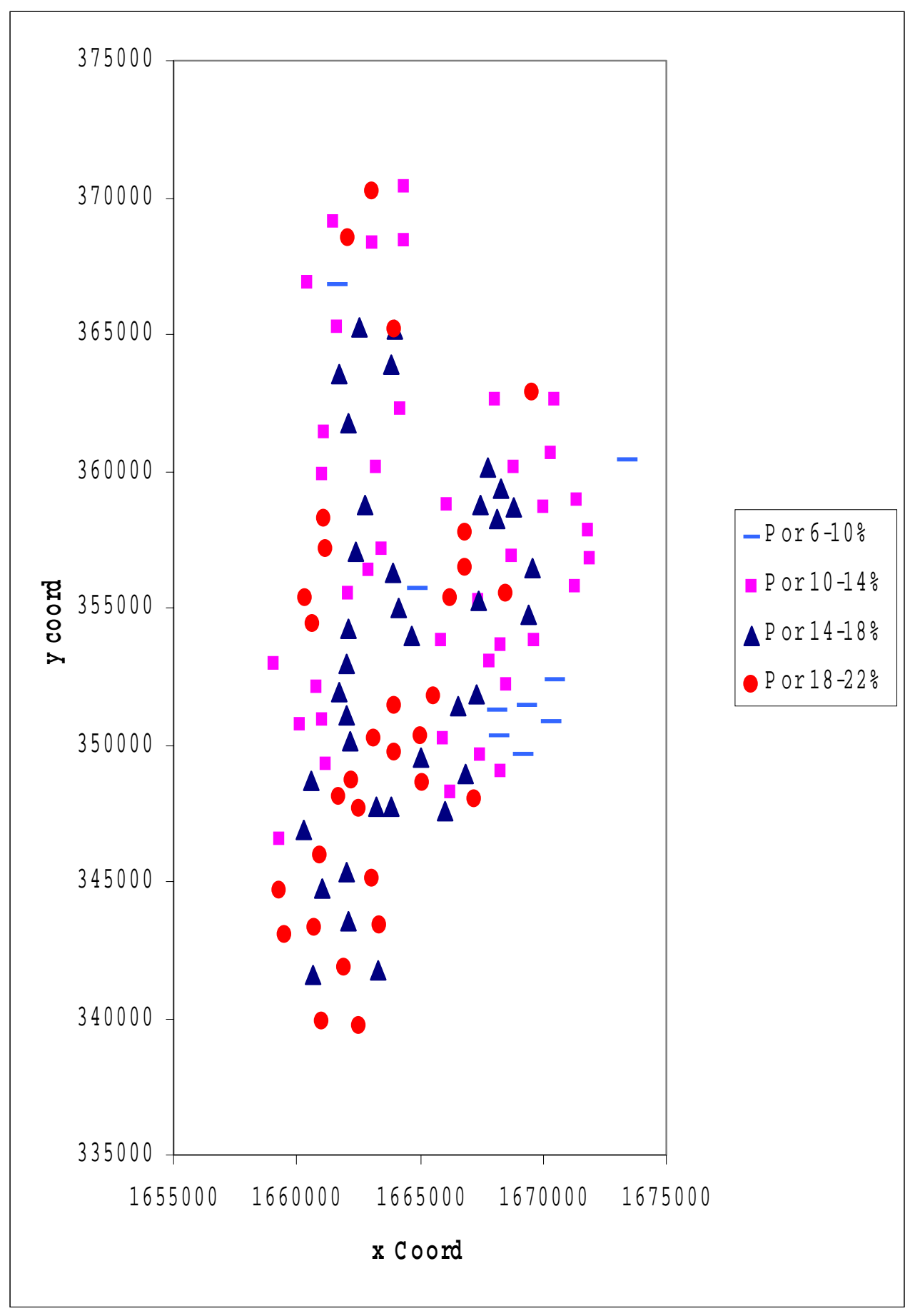




\section{CHAPTER 5}

\section{CONCLUSIONS AND RECOMMENDATIONS}

The results indicated that the approach used by applying ANN is useful for the predicting of porosity. The developed artificial neural network was able to obtain a correlation between $\log$ porosity and core porosity with $\mathrm{R}^{2}$ ratio of 0.917 . The correlation function is $\mathrm{y}=1.1063 \mathrm{x}-1.3943$, where $\mathrm{x}$ represents $\log$ porosity and $\mathrm{y}$ corresponds to the core porosity obtained by ANN. The comparison between actual core porosity and ANN predictions show that a correlation can be made. However, there are two wells, which show low correlation between core porosity and ANN prediction. This may be attributed to the heterogeneity of the reservoir or change in the matrix density. Also, problems such as inaccuracies in core porosity, thin pay zones, few data point per well may have an impact on the prediction performance. Nevertheless, the predicted results of this study were satisfactory.

Virtual measurement predicts more accurately than the conventional log method. The main reason for virtual measurement's superiority is its use of artificial neural networks. This study shows that artificial neural network estimation of formation porosity by use of well $\log$ is a feasible methodology. Also, we present GRNN as capable of predicting formation porosity. We also demonstrated that the trained network was able to estimate porosity comparable to that of actual core measurements. It is plausible to develop a correlation between core porosity and log porosity, which can be used to predict the porosity in a heterogeneous reservoir. The conventional core (plug) analysis must be available to achieve a reasonable porosity correlation between core and 
$\log$ data. The geological interpretations, geophysical well log responses are required for the porosity correlation purposes. Virtual Measurement technique, which incorporates artificial neural networks to be used to predict porosity values throughout the field, seems to be the most promising one in the literature.

Integrating geological interpretations, trend variations per location and more log data, such as resistivity logs, may help to further substantiate any decision to divide the heterogeneous formation into several zones and find a better correlation with less scatter for the main pay. Also, taking measurements from available core and including new analysis tool may help the Neural Network's Predictions. Also, adding variables such as gamma ray and bulk density second derivatives might improve the neural network prediction. 


\section{REFERENCES}

[1] Mohaghegh, S., Arefi, R., Bilgesu, H. I., Ameri, S., Rose, D. "Design and Development of an Artificial Neural Network for Estimation of Formation Permeability", SPE 28237, Proceedings of SPE Petroleum Computer Conference, Dallas, TX, July-August 1994.

[2] Mohaghegh, Ameri, S., Arefi, R., "Virtual Measurement of Heterogeneous Formation Permeability Using Geophysical Well Log Responses”, Log Analyst, March-April 1996

[3] Balan, B., Mohaghegh, S., Ameri, S., "State-Of-The-Art Permeability Determination From Well Log Data: Part 1 - A Comparative Study, Model Development", SPE 30978, Proceedings of SPE Eastern Regional Meeting, Morgantown, WV, September 1995.

[4] Howard B. Bradley "Petroleum Engineering Handbook", Society of Petroleum Engineers, Richardson, TX, February 1992

[5] D. Dashevskiy, V. Dubinsky, J. D. Macpherson “Application of Neural Networks for Predictive Control in Drilling Dynamics", SPE 56442, SPE Annual Technical Conference and Exhibition, Houston, TX, October 1999

[6] NeuroShell 2 Help File, (C) Ward Systems Group, Inc.

[7] A. Ouenes, S. Richardson and W. W. Weiss "Fractured reservoir Characterization and Performance Forecasting Using Geomechanics and Artificial Intelligence", SPE 30572, SPE Annual Techanical Conference and Exhibition, Dallas, TX, October 1995 
[8] Kumoluyi, A., Daltaban, T., "Higher-Order Neural Networks in Petroleum Engineering”, SPE 27905 Proceeding of SPE Western Regional Meeting, Long Beach, CA, March 1994

[9] Molnar, D., Aminian, K., Ameri, S., "The Use of Well Log Data for Estimating Permeability in a Heterogeneous Reservoir", SPE 29175, Proceedings of SPE Eastern Regional Meeting, Charleston, WV, November 1994.

[10] Mohaghegh, S., "Neural Network: What It Can Do for Petroleum Engineers", JPT Magazine, January 1995.

[11] Ameri, S., Molnar, D., Mohaghegh, S. and Aminian, K., "Permeability Evaluation in Heterogeneous Formations Using Geophysical Well Logs and Geological Interpretations", SPE 26060, Proceedings of SPE Western Regional Meeting, Anchorage, Alaska, May 1993.

[12] Mohaghegh, S., Arefi, R., Ameri, S., "A Methodological Approach for Reservoir Heterogeneity Characterization Using Artificial Neural Networks", SPE 28394, Proceedings of SPE Annual Conference, New Orleans, LA, September 1994.

[13] Mohaghegh, S., Ameri, S., Arefi, R., "Virtual Measurement of Heterogeneous Formation Permeability Using Geophysical Well Log Responses”, Log Analyst, March-April 1996 


\section{APPENDIX I}

Core Porosity vs. Log Porosity Plots 
Figure I - 1 Core Porosity vs. Log Porosity for Well 095-0741

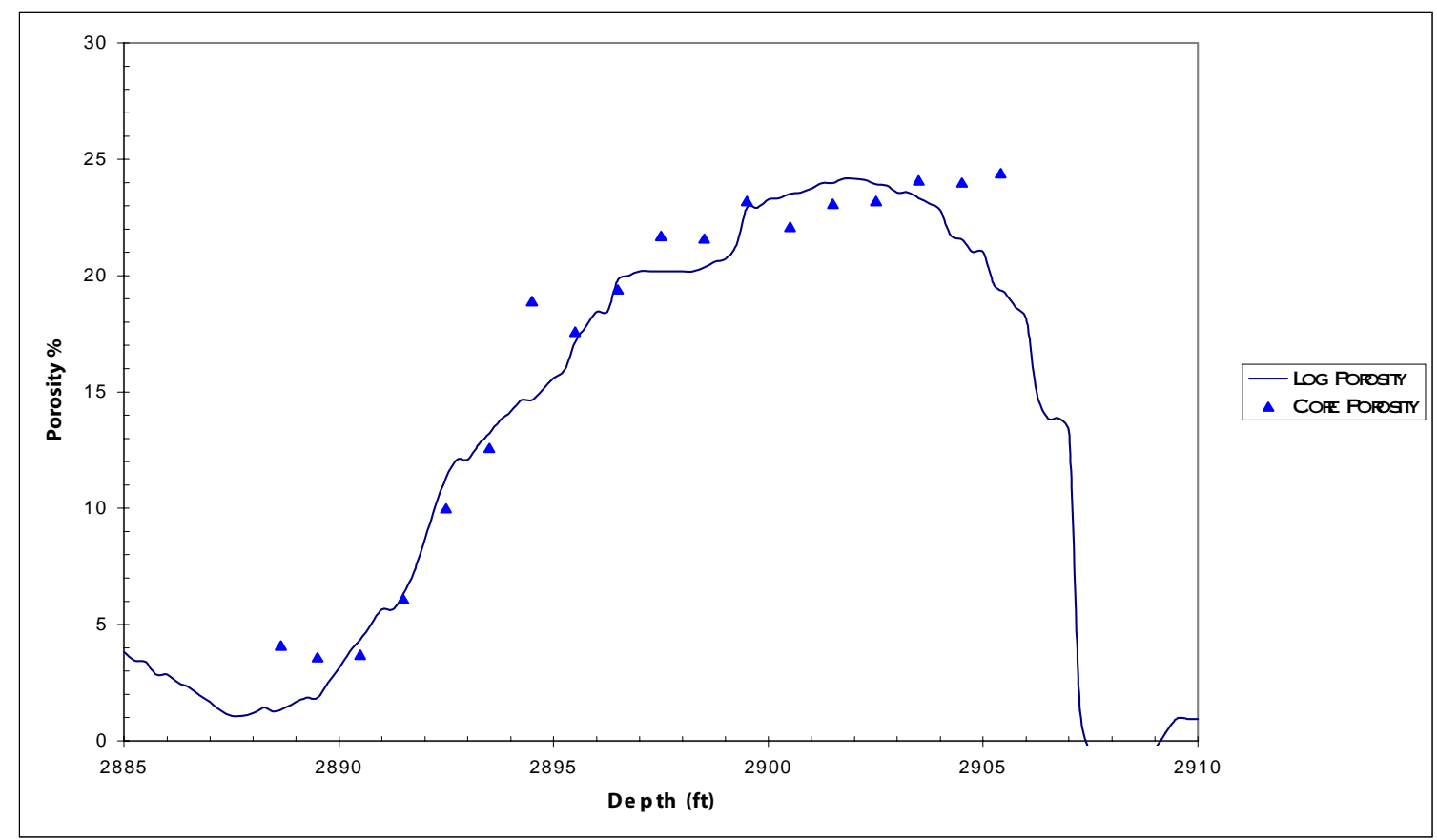

Figure I - 2 Core Porosity vs. Log Porosity for Well 095-0859

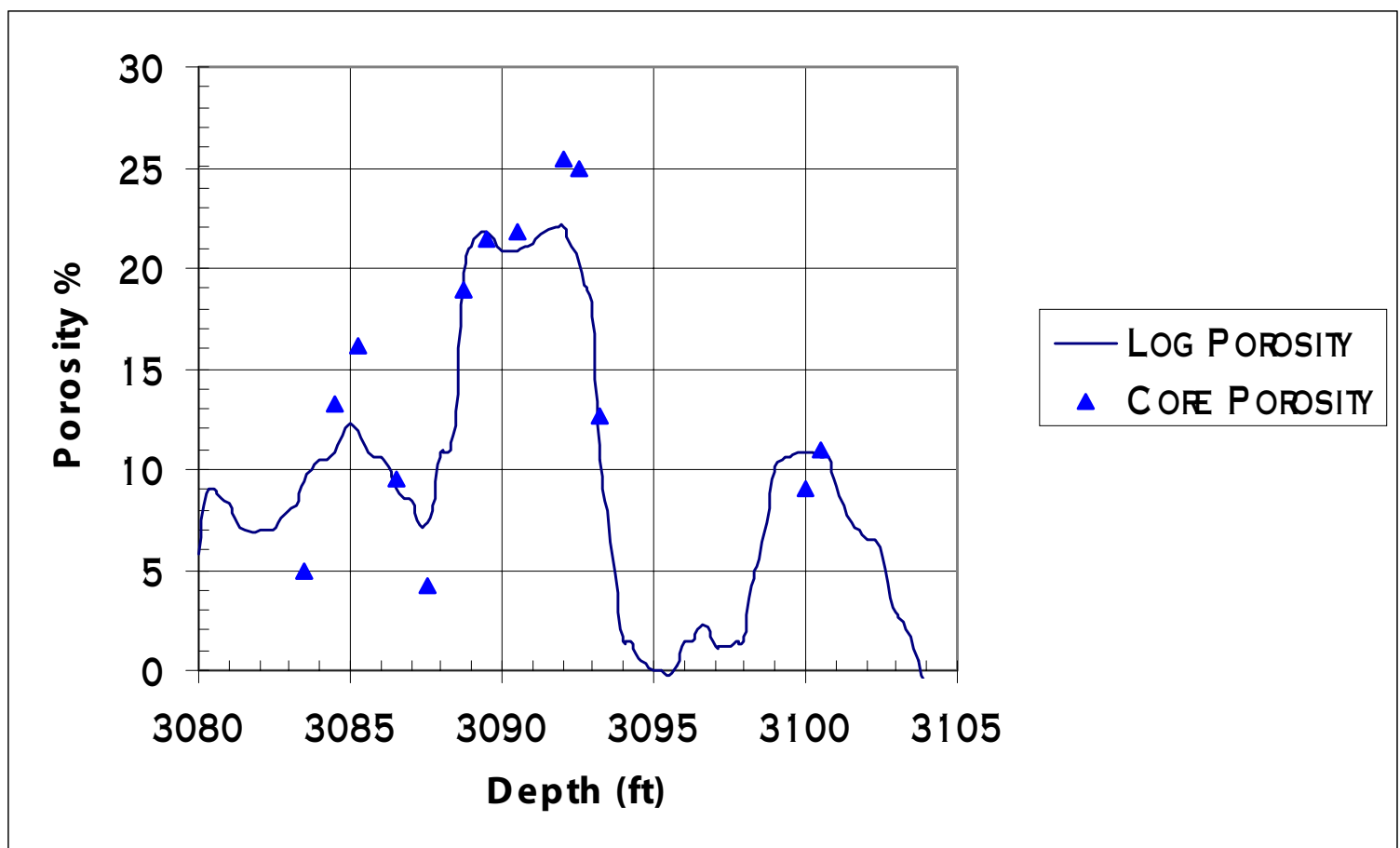


Figure I - 3 Core Porosity vs. Log Porosity for Well 095-1124

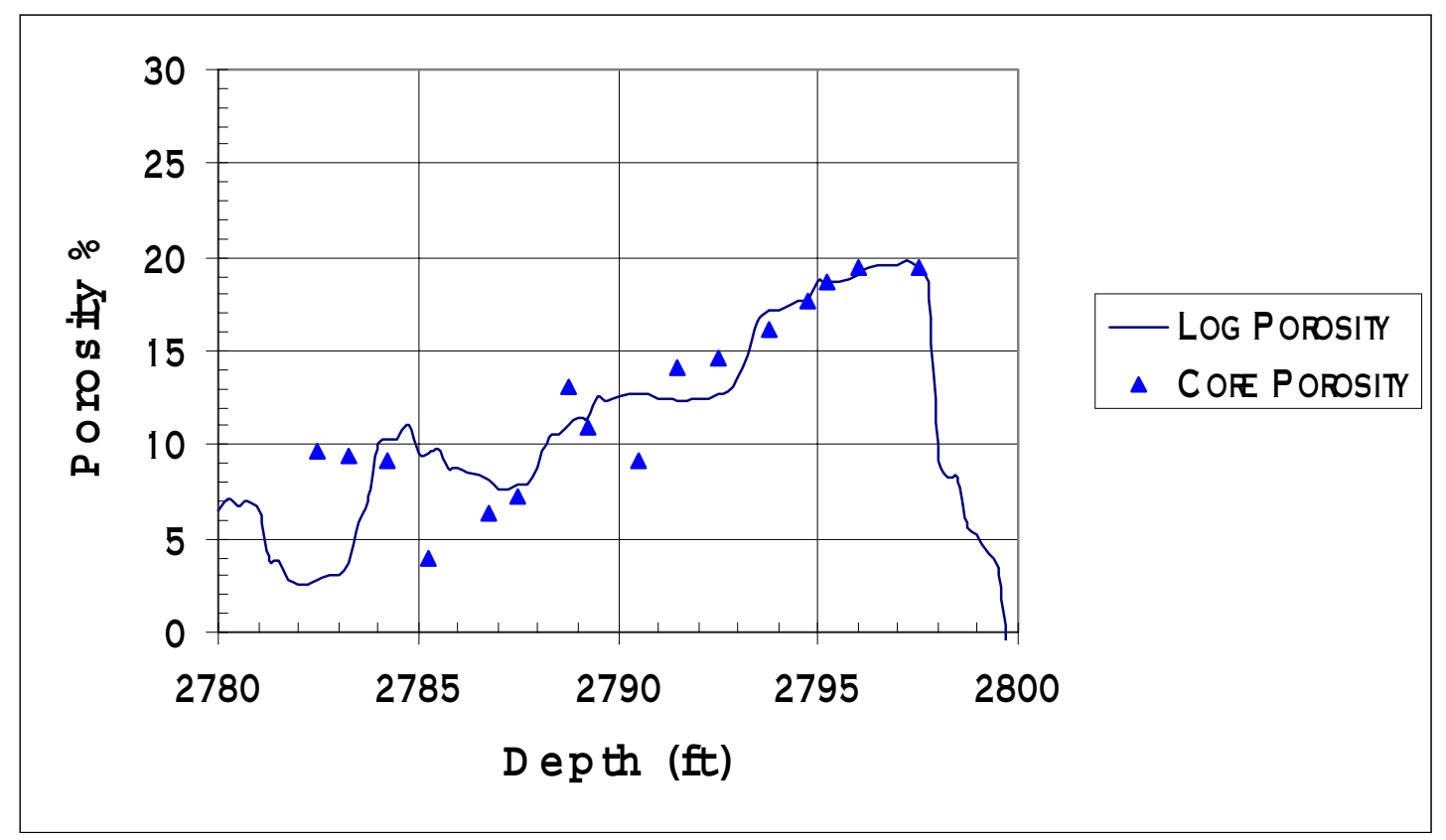

Figure I - 4 Core Porosity vs. Log Porosity for Well 095-1126

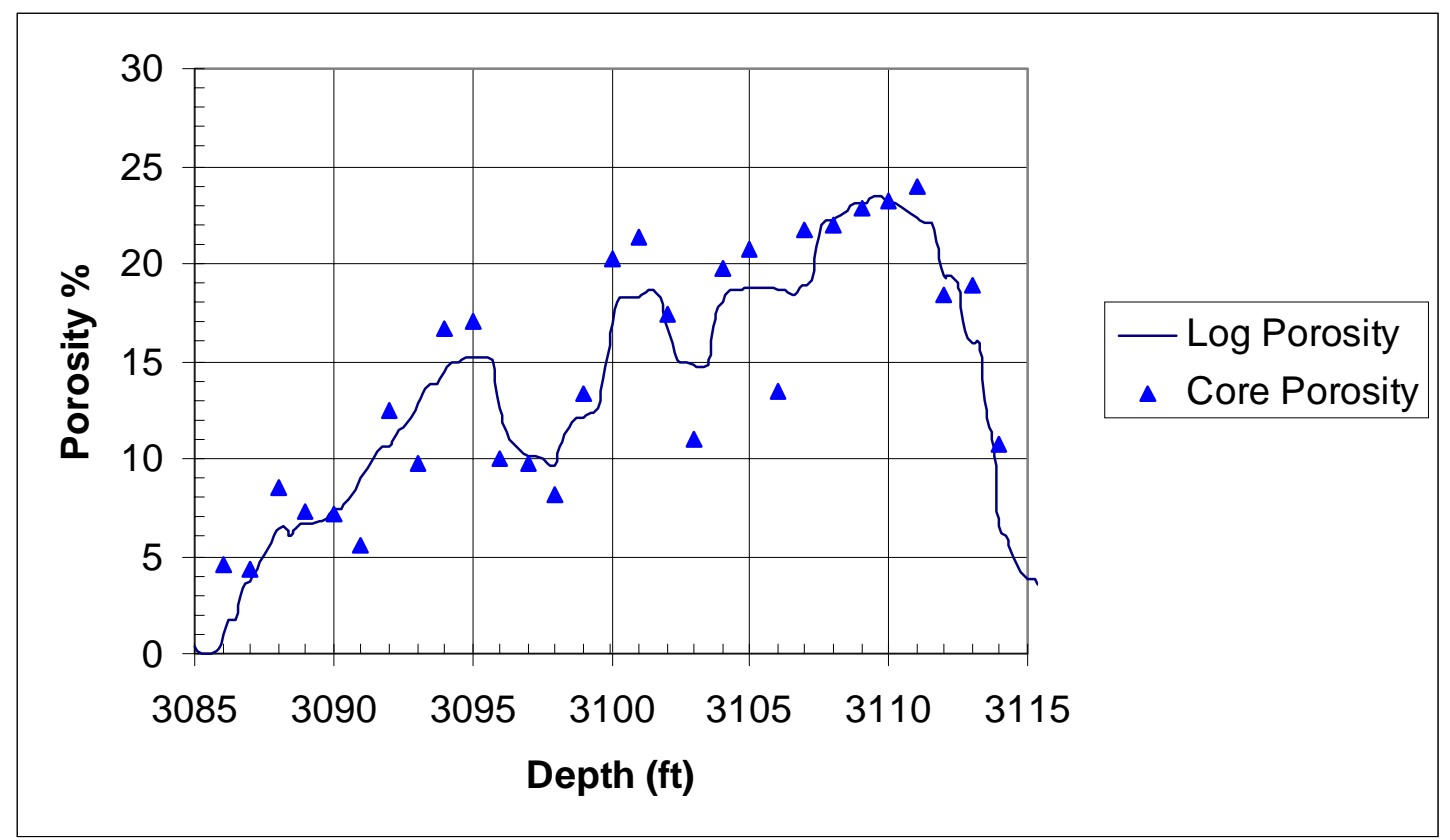


Figure I - 5 Core Porosity vs. Log Porosity for Well 103-1315

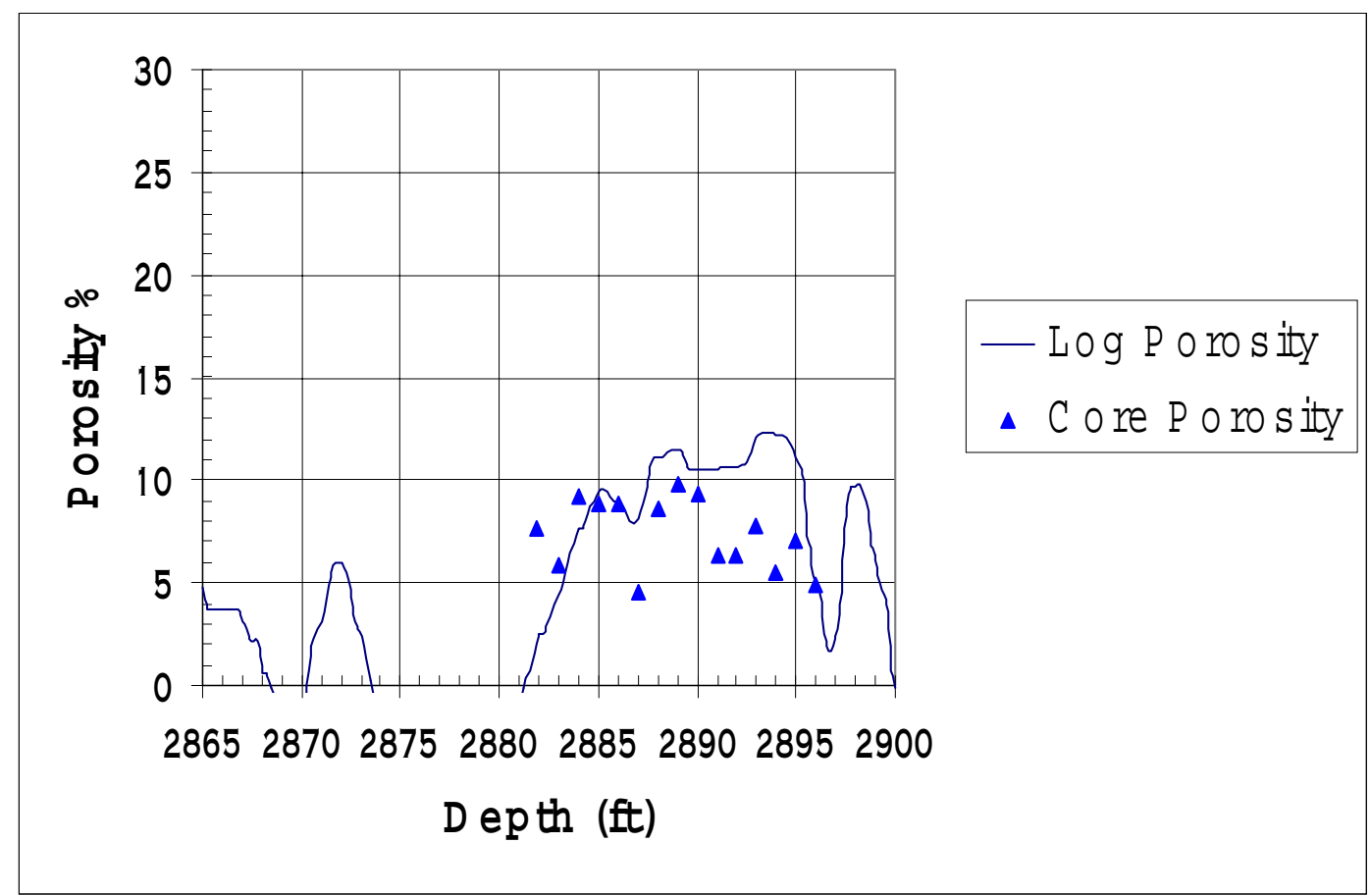

Figure I - 6 Core Porosity vs. Log Porosity for Well 103-1547

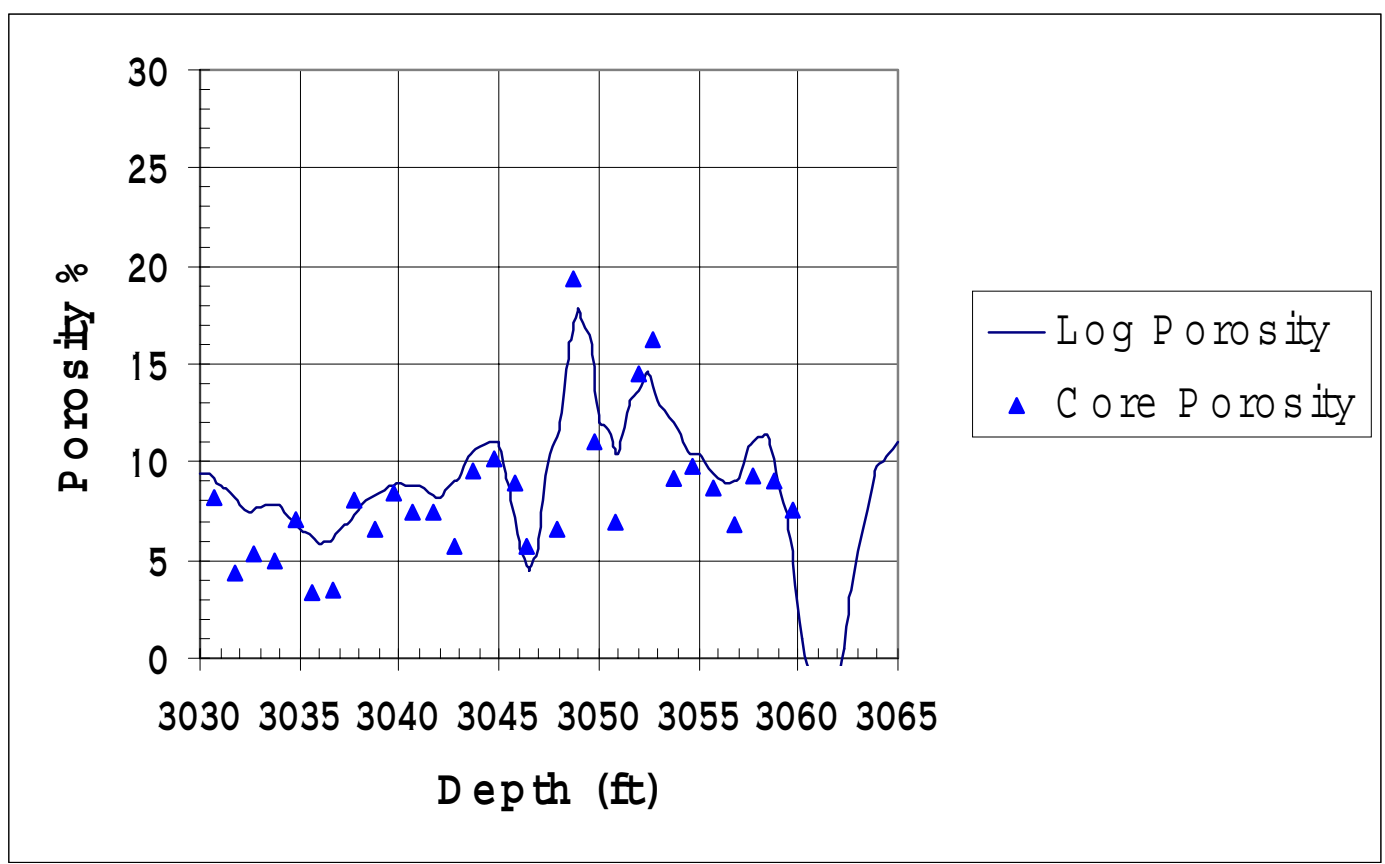




\section{APPENDIX II}

Plots of Core Porosity and Log Responses vs. Depth 
Figure II - 1 Core Porosity and Log Responses vs. Depth for Well 095-0741

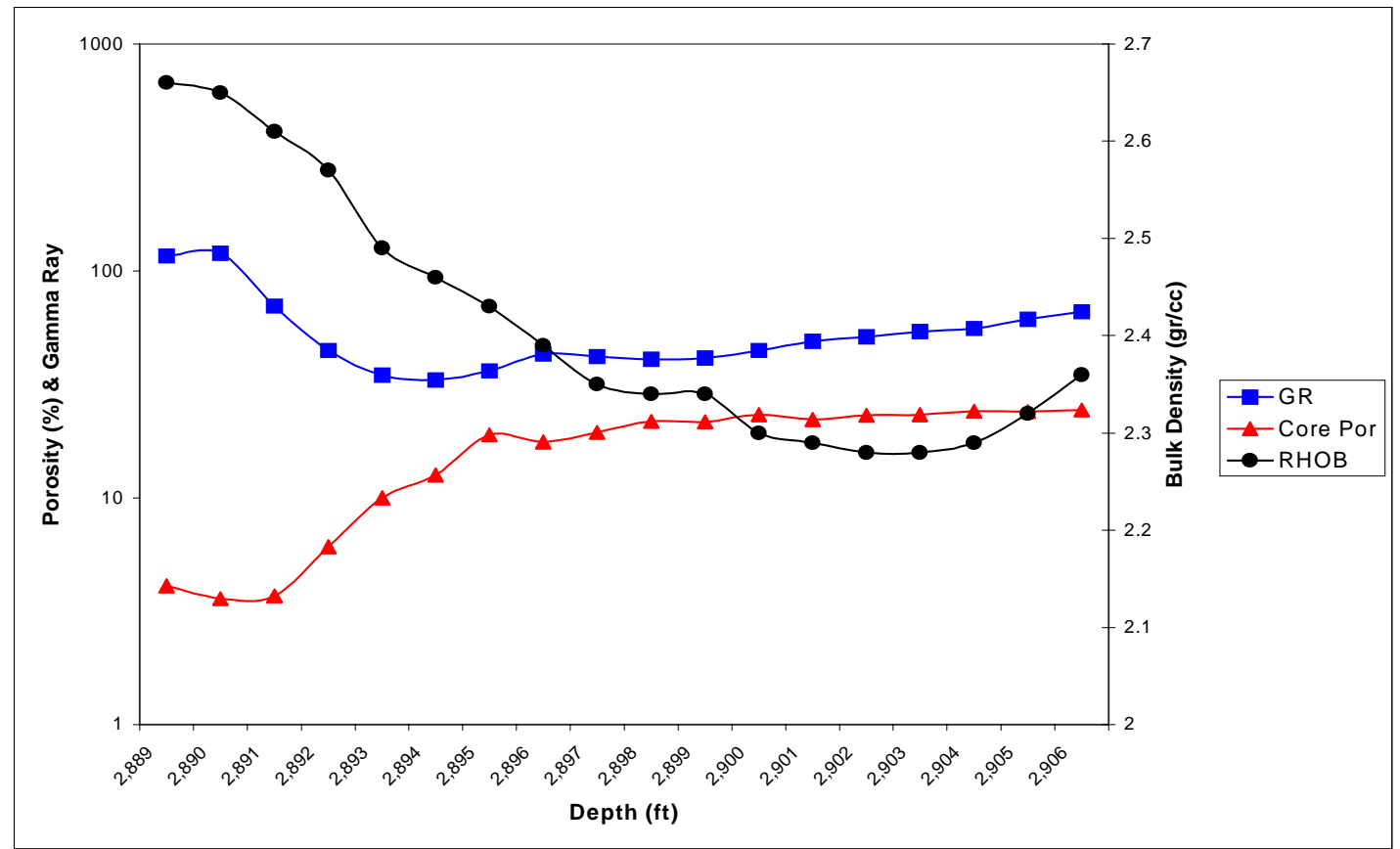

Figure II - 2 Core Porosity and Log Responses vs. Depth for Well 095-0859

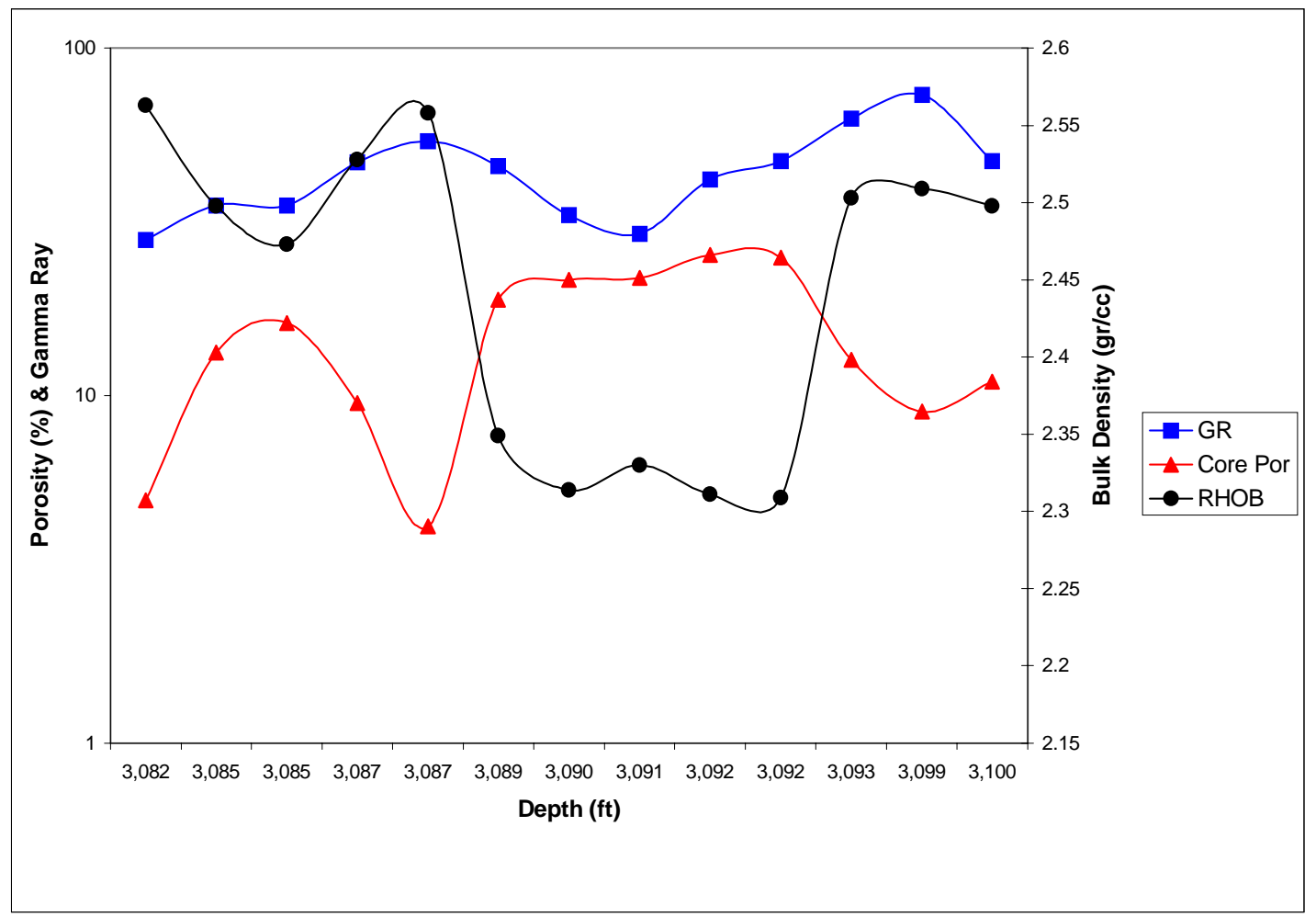


Figure II - 3 Core Porosity and Log Responses vs. Depth for Well 095-1125

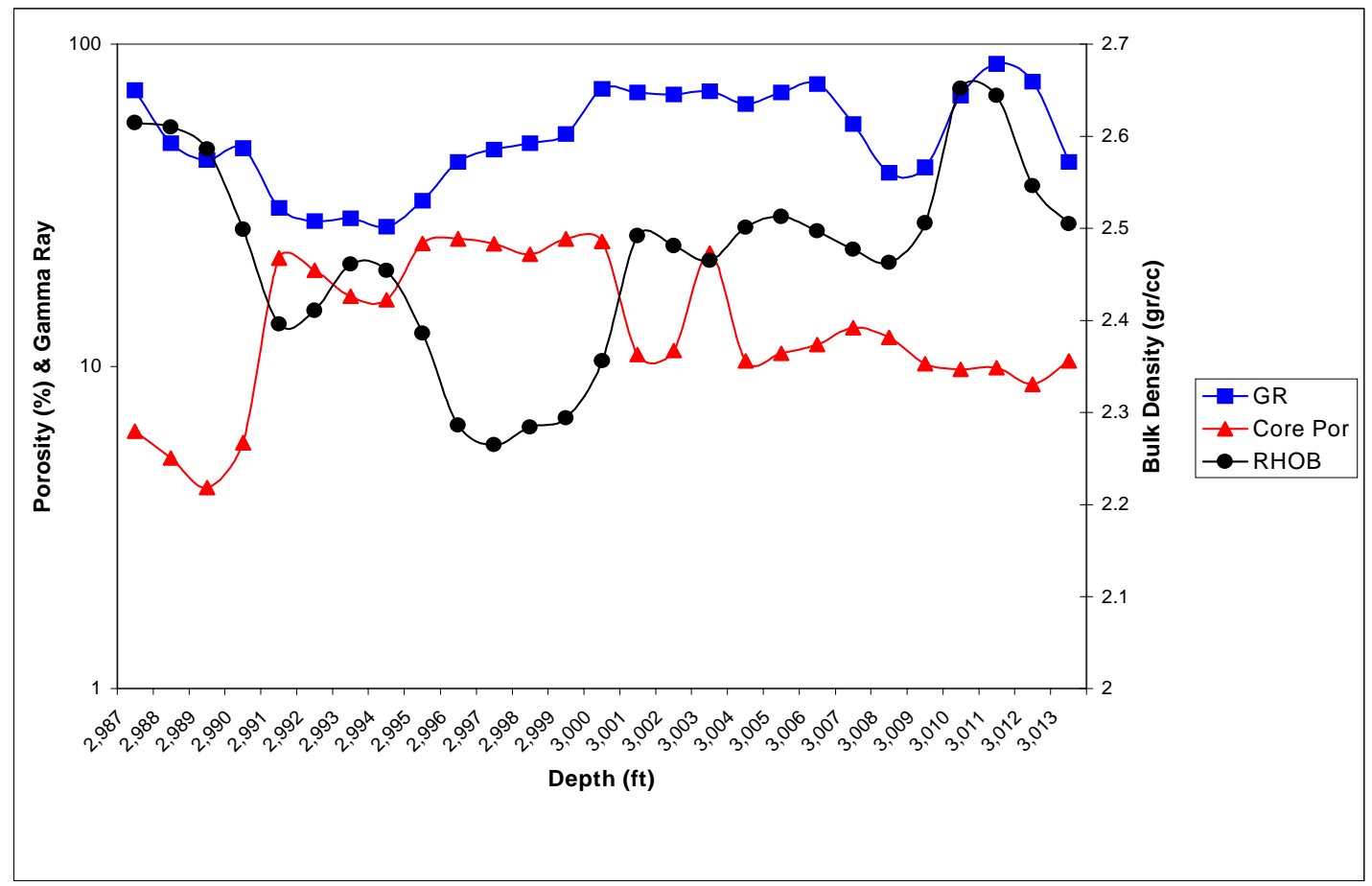

Figure II - 4 Core Porosity and Log Responses vs. Depth for Well 095-1126

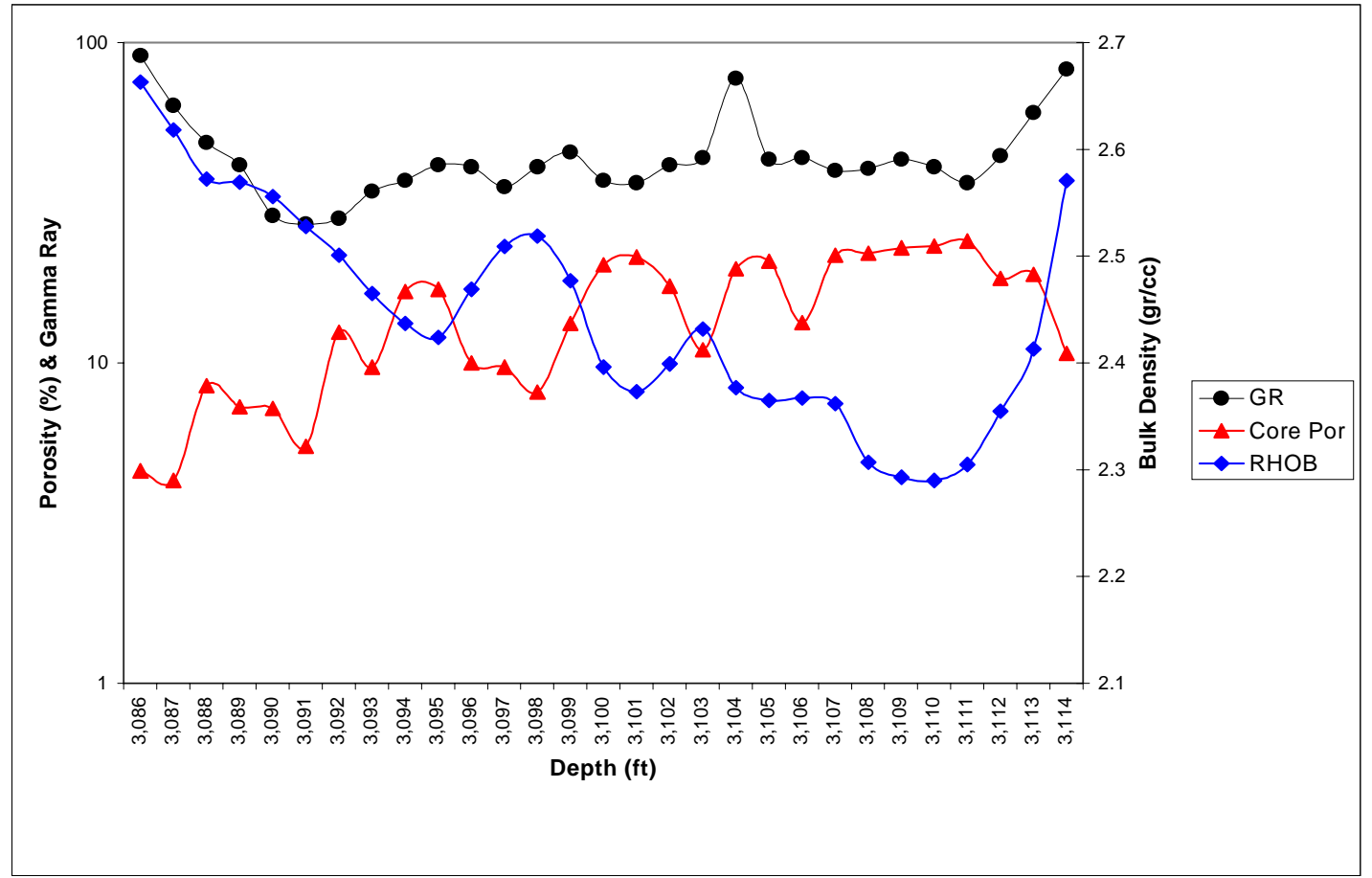


Figure II - 5 Core Porosity and Log Responses vs. Depth for Well 103-1315

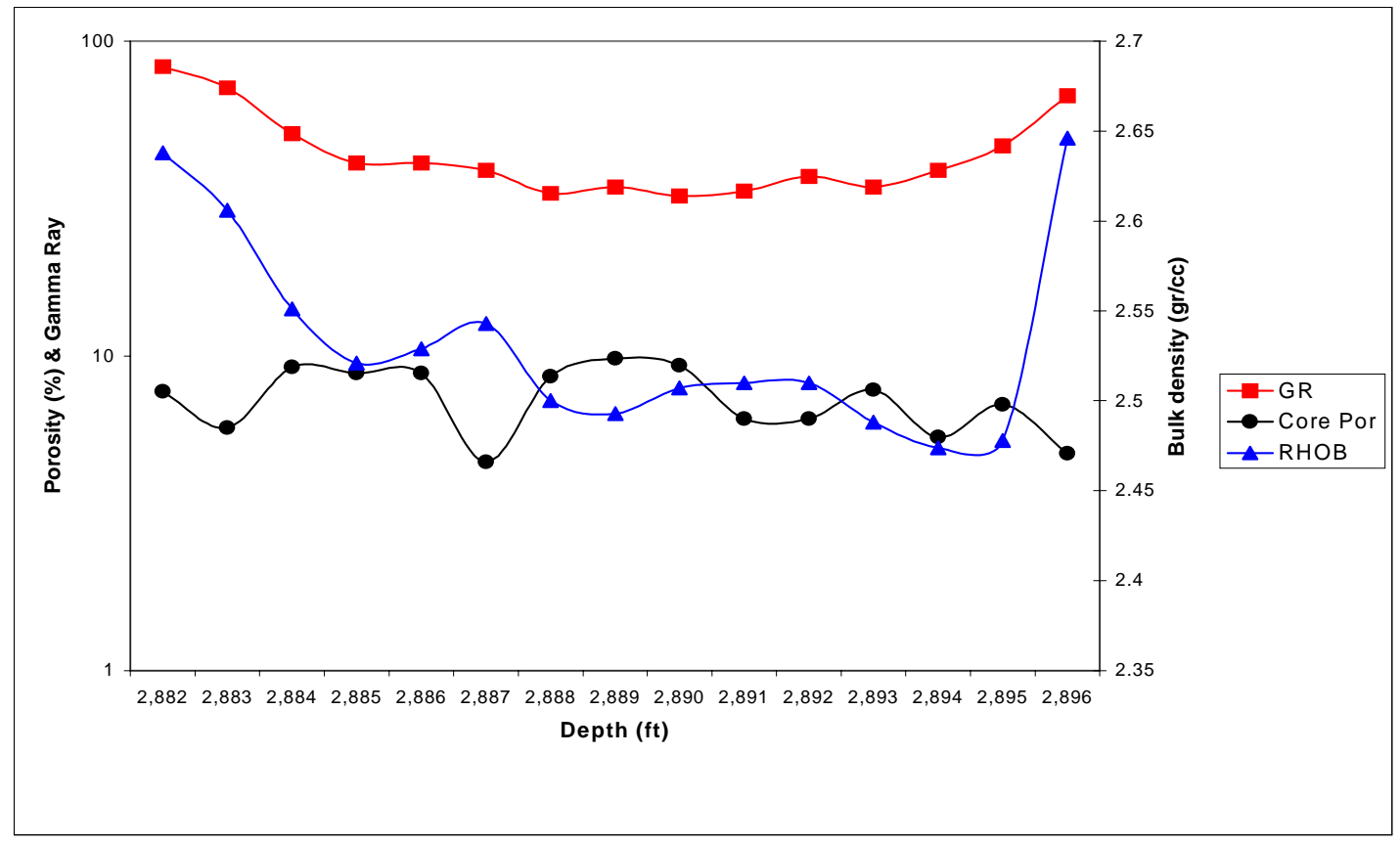

Figure II - 6 Core Porosity and Log Responses vs. Depth for Well 103-1547

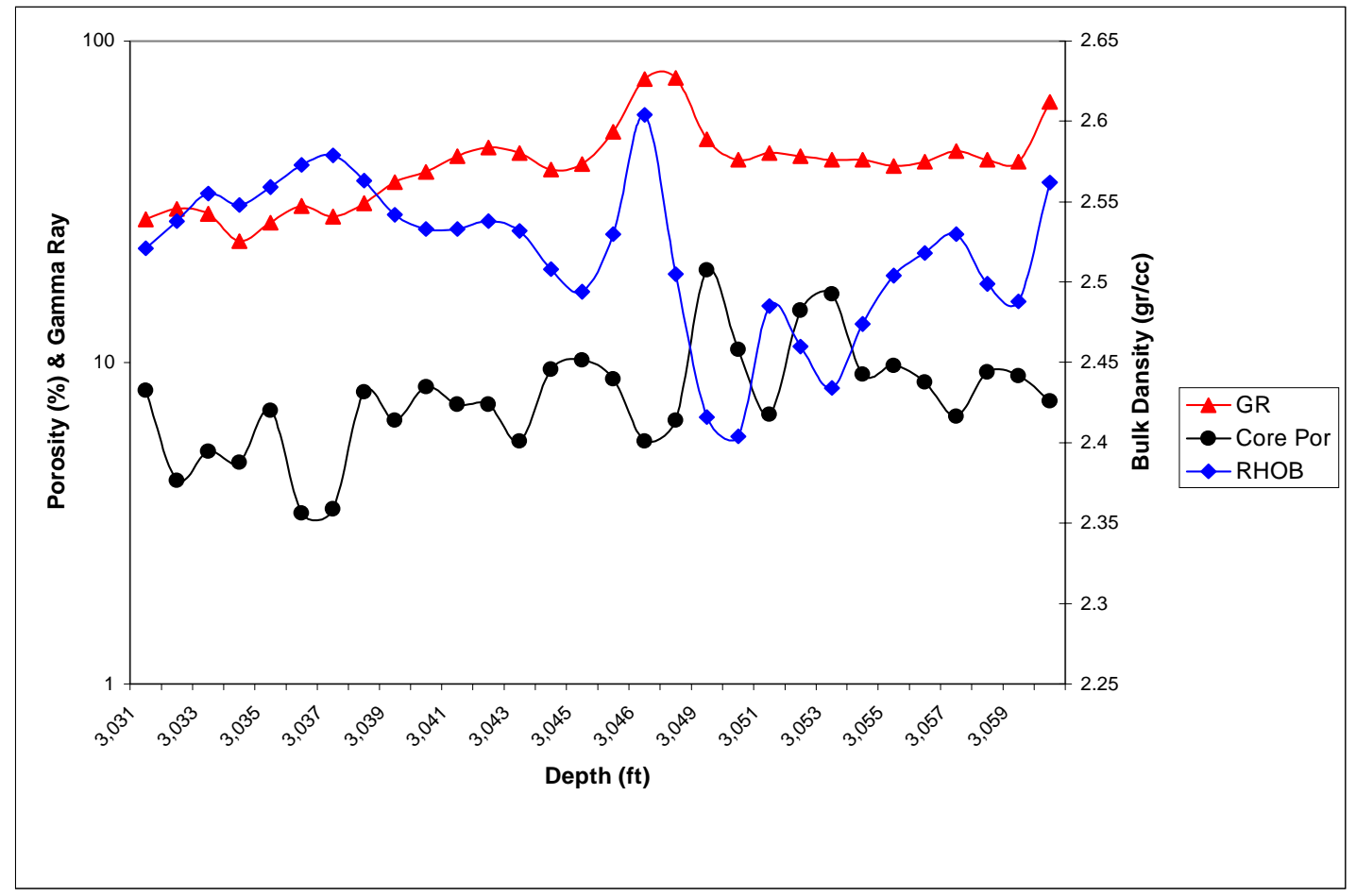

